\title{
Emended description of the order Chlamydiales, proposal of Parachlamydiaceae fam. nov. and Simkaniaceae fam. nov., each containing one monotypic genus, revised taxonomy of the family Chlamydiaceae, including a new genus and five new species, and standards for the identification of organisms
}

\author{
Karin D. E. Everett, ${ }^{1} \dagger$ Robin M. Bush ${ }^{2}$ and Arthur A. Andersen ${ }^{1}$
}

Author for correspondence: Karin D. E. Everett. Tel: +1 706542 5823. Fax: +1 7065425771. e-mail: keverett@calc.vet.uga.edu orkdeeverett@hotmail.com

\footnotetext{
1 Avian and Swine Respiratory Diseases Research Unit, National Animal Disease Center, Agricultural Research Service, US Department of Agriculture, PO Box 70, Ames, IA 50010, USA

2 Department of Ecology \& Evolutionary Biology, University of California at Irvine, Irvine, CA 92696, USA
}

The current taxonomic classification of Chlamydia is based on limited phenotypic, morphologic and genetic criteria. This classification does not take into account recent analysis of the ribosomal operon or recently identified obligately intracellular organisms that have a chlamydia-like developmental cycle of replication. Neither does it provide a systematic rationale for identifying new strains. In this study, phylogenetic analyses of the 165 and 235 rRNA genes are presented with corroborating genetic and phenotypic information to show that the order Chlamydiales contains at least four distinct groups at the family level and that within the Chlamydiaceae are two distinct lineages which branch into nine separate clusters. In this report a reclassification of the order Chlamydiales and its current taxa is proposed. This proposal retains currently known strains with $>90 \% 165$ rRNA identity in the family Chlamydiaceae and separates other chlamydia-like organisms that have $80-90 \% 165$ rRNA relatedness to the Chlamydiaceae into new families. Chlamydiae that were previously described as 'Candidatus Parachlamydia acanthamoebae' Amann, Springer, Schönhuber, Ludwig, Schmid, Muller and Michel 1997, become members of Parachlamydiaceae fam. nov., Parachlamydia acanthamoebae gen. nov., sp. nov. 'Simkania' strain $\mathrm{Z}$ becomes the founding member of Simkaniaceae fam. nov., Simkania negevensis gen. nov., sp. nov. The fourth group, which includes strain WSU 86-1044, was left unnamed. The Chlamydiaceae, which currently has only the genus Chlamydia, is divided into two genera, Chlamydia and Chlamydophila gen. nov. Two new species, Chlamydia muridarum sp. nov. and Chlamydia suis sp. nov., join Chlamydia trachomatis in the emended genus Chlamydia. Chlamydophila gen. nov. assimilates the current species, Chlamydia pecorum, Chlamydia pneumoniae and Chlamydia psittaci, to form Chlamydophila pecorum comb. nov., Chlamydophila pneumoniae comb. nov. and Chlamydophila psittaci comb. nov. Three new Chlamydophila species are derived from Chlamydia psittaci: Chlamydophila abortus gen. nov., sp. nov., Chlamydophila caviae gen. nov., sp. nov. and Chlamydophila felis gen. nov., sp. nov. Emended descriptions for the 


\section{order Chlamydiales and for the family Chlamydiaceae are provided. These families, genera and species are readily distinguished by analysis of signature sequences in the $16 \mathrm{~S}$ and 235 ribosomal genes.}

Keywords: Chlamydiales, taxonomy, ribosomal, human pathogens, animal pathogens

\section{INTRODUCTION}

Members of the order Chlamydiales are obligately intracellular bacteria. They exhibit a two-stage developmental cycle of replication: the infectious bacterial form is endocytosed by eukaryotic cells and resides within a cytoplasmic inclusion, where it transforms into a vegetative form and replicates by binary fission (Moulder, 1991). As an inclusion fills with progeny, chlamydiae transform back into the metabolically inactive, infectious form and are released through host cell rupture or fusion of the inclusion/ plasma membranes. Chlamydiae are disseminated by aerosol or by contact, requiring no alternate vector. Of the fifteen or more major groupings in the domain Bacteria (Stackebrandt et al., 1997; Van de Peer et al., 1994), Chlamydiales is the only lineage whose known members are exclusively intracellular parasites of members of the domain Eucarya.

The order Chlamydiales currently has one family, the Chlamydiaceae, containing one genus and four species (Herring, 1993). When the Approved Lists of Bacterial Names was published in 1980, the Chlamydiaceae had just two species (Skerman et al., 1980). At that time, all bacteria with chlamydia-like chemical characteristics, morphology and developmental replication belonged to either Chlamydia trachomatis or Chlamydia psittaci in the order Chlamydiales (Page, 1966, 1968; Storz \& Page, 1971). Chlamydia trachomatis strains were identified by their accumulation of glycogen in inclusions and their sensitivity to sulfadiazine. Chlamydia psittaci strains did not accumulate glycogen and were usually resistant to sulfadiazine. The establishment of this classification was a milestone in chlamydial taxonomy, as it renounced reliance on presumed host, on presumed tissue preference and on serology in grouping these organisms.

Before 1980, however, isolations had already been made that would not fit into these two species (Darougar et al., 1980; Dwyer et al., 1972; Forsey \& Darougar, 1984). The development of DNA-based classification methods during the 1980 s provided new techniques for differentiating chlamydial groups. DNA-DNA reassociation, in particular, was established as a tool for distinguishing species $(<70 \%$ homology) and genera ( $<20 \%$ homology) (Amann et al., 1995; Schleifer \& Stackebrandt, 1983; Wayne et al., 1987). According to these criteria, DNA-DNA reassociation studies of new chlamydial strains and of strains placed in the ATCC collection prior to 1971 supported eight groups on the level of genus or species (Table 1). These data contributed to the creation of two additional species, Chlamydia pneumoniae
(Grayston et al., 1989) and Chlamydia pecorum (Fukushi \& Hirai, 1992). In 1993, DNA sequence analysis identified an isolate from a ninth chlamydial group, Chlamydia trachomatis-like Chlamydia from swine (Kaltenboeck et al., 1993). Since then, a number of closely related swine isolates and variants have been reported (Everett \& Andersen, 1997; Kaltenböck et al., 1997; Kaltenboeck \& Storz, 1992; Rogers et al., 1993, 1996; Rogers \& Andersen, 1996; Schiller et al., 1997). These strains cannot be designated as Chlamydia trachomatis using current criteria, as many of these strains are resistant to sulfadiazine (Andersen \& Rogers, 1998). The nine clusters in the Chlamydiaceae are supported by analyses of phenotype, antigenicity, associated disease, host range, biological data and genomic endonuclease restriction (Everett \& Andersen, 1997). Genetic data, including recent phylogenetic analyses using the ribosomal operon, are also consistent with the presence of nine groups in the Chlamydiaceae (Everett \& Andersen, 1997; Kaltenboeck et al., 1993; Pudjiatmoko et al., 1997; Takahashi et al., 1997).

Species within the Chlamydiaceae have 16S rRNA gene sequences that are $>90 \%$ identical (Pettersson et al., 1997; Pudjiatmoko et al., 1997; Takahashi et al., 1997). All strains in the Chlamydiaceae are recognized by monoclonal antibodies (mAbs) that detect the LPS trisaccharide $\alpha \mathrm{Kdo}-(2 \rightarrow 8)-\alpha \mathrm{Kdo}-(2 \rightarrow 4)-\alpha \mathrm{Kdo}$ (Löbau et al., 1995). Four additional groups of chlamydia-like organisms have been recently identified that have $>80 \% 16 \mathrm{~S}$ rRNA gene sequence identity with chlamydiae: (i) the 'Simkania' strain Z (Kahane et al., 1995, 1999); (ii) strains of 'Hall's coccus' (Birtles et al., 1997) and the closely related 'Candidatus Parachlamydia acanthamoebae' Amann et al. 1997 (Amann et al., 1997), all of which were isolated from amoebae; (iii) an agent identified as a cause of bovine abortion that was initially described as a rickettsia (Dilbeck et al., 1990; Kocan et al., 1990; Rurangirwa et al., 1999); and (iv) a cluster of isolates from amoebae (T. Fritsche, personal communication; Gautom et al., 1996). These bacteria meet the requirement for inclusion in Chlamydiales because they are obligate intracellular bacteria that have the chlamydia-like developmental cycle of replication. Inclusion of these novel chlamydia-like agents in Chlamydiales meets criteria recently established to define a bacterial class based exclusively on $>80 \% 16 \mathrm{~S}$ rRNA gene sequence identity (Stackebrandt et al., 1997). However, because the new groups at present include just a few species, a decision regarding whether Chlamydiales should become a class or remain an order can be deferred until more information on these and other new chlamydial 
Table 1. Chlamydia spp. percentage similarity using DNA-DNA reassociation (Chlamydia suis not tested)

The total number of strains $(n)$ that were used in these studies is shown for each species in the row heading, but many of the comparisons were performed with only a subset of these strains.

\begin{tabular}{|c|c|c|c|c|c|c|c|c|}
\hline & 8 & 7 & 6 & 5 & 4 & 3 & 2 & 1 \\
\hline 1 Chlamydia trachomatis $(n=8)$ & $\leqslant 5^{*}$ & $6-11^{*}, 18-24 \dagger$ & $\leqslant 5-6^{*}, 5-15 \dagger$ & $\begin{array}{c}7-12+, 11 \S, \leqslant 5^{*}, \\
15-33 \dagger\end{array}$ & $4-32 \dagger$ & $\leqslant 5-7^{*}$ & $65 \S, 20-52 \dagger$ & $\begin{array}{c}100+\$, 97-100^{*} \\
92-100 \dagger\end{array}$ \\
\hline 2 Chlamydia muridarum $(n=1)$ & - & $1-10^{\dagger}$ & $2-6 \dagger$ & $11 \S, 3-20 \dagger$ & $1-4 \dagger$ & - & $100^{\dagger}$ & \\
\hline 3 Chlamydophila pneumoniae $(n=4)$ & $\leqslant 5-8^{*}$ & $68^{*}$ & $6-10^{*}$ & $\leqslant 5-7^{*}$ & 109 & $94-100^{*}, 94-969$ & & \\
\hline 4 Chlamydophila pecorum $(n=3)$ & - & $9-12 \dagger$ & $1 \dagger$ & $1-19 \dagger$ & $88-100 \dagger$ & & & \\
\hline 5 Chlamydophila psittaci $(n=6)$ & $20-35^{*}$ & $21-37^{*}, 31-33+$ & $63-85^{*}, 27-85^{\dagger}$ & $\begin{array}{c}100+\S, 93-100^{*}, \\
73-100 \dagger\end{array}$ & & & & \\
\hline 6 Chlamydophila abortus $(n=2)$ & $27-38^{*}$ & $24-37^{*}, 14-33 \dagger$ & $100^{*} \dagger$ & & & & & \\
\hline 7 Chlamydophila felis $(n=2)$ & $30-33^{*}$ & $100 * \dagger$ & & & & & & \\
\hline 8 Chlamydophila caviae $(n=1)$ & $100^{*}$ & & & & & & & \\
\hline
\end{tabular}

* Cox et al. (1988).

$\dagger$ Fukushi \& Hirai (1989). Note also that interspecies analyses were carried out with one Chlamydophila pecorum strain, and that Chlamydophila pecorum intraspecies analysis used three.

$¥$ Kingsbury \& Weiss (1968).

$\S$ Weiss et al. (1970).

๑f Fukushi \& Hirai (1992).

groups has become available. It seems likely that culture-free PCR techniques and DNA sequencing will soon expand our understanding of diversity within Chlamydiales and this will help resolve questions about higher level classification.

A reclassification of chlamydiae based on 16S rRNA sequence similarity clusters, on analyses of full-length $16 \mathrm{~S}$ and $23 \mathrm{~S}$ rDNAs, and on phenotypic and ecologic differentiation (Palys et al., 1997) solves a number of current problems in chlamydial taxonomy. It provides a consistent method for identifying present taxa and a logical basis for defining new taxa using criteria that are comparable to those being established for other major bacterial lineages. It provides appropriate groupings for pathogens with distinctive underlying genetic relationships and diverse, well-established patterns of virulence. It further provides a usable system for organizing chlamydial data in the international sequence databases.

The purpose of this report is to update the description of taxa in the order Chlamydiales, presenting criteria that distinguish Parachlamydiaceae fam. nov., Simkaniaceae fam. nov. and Chlamydiaceae and designating appropriate genera and species within the Chlamydiaceae. To accomplish this, phylogenetic trees were constructed using $16 \mathrm{~S}$ and 23S rRNA sequences from a number of strains within the Chlamydiaceae and closely related strains. To aid in the identification of new strains, 'signature sequence' segments for PCR amplification and sequencing were identified in the $16 \mathrm{~S}$ and $23 \mathrm{~S}$ rRNA genes. Information was compiled for the descriptions of species, chlamydial genome sizes and the presence or the absence of extrachromosomal plasmids. We offer the following proposal for revision of groupings within the order Chlamydiales, with two new families within the Chlamydiales and establishing a new genus and five new species in the Chlamydiaceae.
In this paper, the new names or combinations have only been used in the text following their first mention in the descriptions. However, the new names and combinations have been used throughout the tables and figures.

\section{METHODS}

Bacterial strains. Chlamydia strains that were used for $23 \mathrm{~S}$ rRNA gene analysis included Chlamydia pneumoniae TW$183^{\mathrm{T}}$, Chlamydia pecorum IPA, Chlamydia psittaci $\mathrm{NJ} 1$, $6 \mathrm{BC}^{\mathrm{T}}$, GPIC, FP Baker, Chlamydia trachomatis A/Har-13 ${ }^{\mathrm{T}}$, L2/434/BU, MoPn, SFPD and the Chlamydia trachomatislike swine strain R22 and were obtained from previously described sources (Everett \& Andersen, 1997). 'Simkania' Z was obtained from preparations of $\mathrm{HeLa}$ and Vero cells, and was identical to 'Simkania' Z1, which was a subculture of 'Simkania' Z (Everett \& Andersen, 1997; Kahane et al., 1993). Strain WSU 86-1044 was obtained from Fred Rurangirwa at the Washington Animal Disease Diagnostic Laboratory (WADDL) in Pullman, WA, USA. Chlamydial strains used for PFGE, extrachromosomal plasmid analysis, and testing of primers for signature sequence analysis were obtained from previously described sources (Everett \& Andersen, 1997). Escherichia coli strain JM109 used in PFGE was obtained from Francis E. Nano (currently at University of Victoria, Victoria, BC, Canada).

Sequence and phylogenetic analysis. Oligonucleotide primer synthesis and DNA sequencing were performed by the Iowa State University DNA Sequencing and Synthesis Facility, Ames, IA, USA. Both the coding and the complementary strands were sequenced. The Sequencher data analysis software (Gene Codes) was used to assemble the 23S rRNA gene sequences. Sequence analysis programs described in the Program Manual for the Wisconsin Package (Genetics Computer Group, 1994) were used for DNA and RNA analyses. These programs were Reformat, SeqEd, Assemble, PILEUP, LineUp, Distances, FoldRNA and SQUIGGLES.

For phylogenetic analyses of the complete $16 \mathrm{~S}$ rRNA genes, sequence data were retrieved from GenBank and extended to full-length as necessary using data from a recent study 
(Everett \& Andersen, 1997). The 16S rDNA from strain SFPD was resequenced; the 16S rRNA and 16S-23S intergenic spacer sequence for strain WSU 86-1044 were provided by Fred Rurangirwa (Department of Veterinary Microbiology and Pathology, Washington State University, Pullman, WA, USA). The 23S rRNA sequences from strain WSU 86-1044 and 'Simkania' strain Z were obtained directly from PCR products. Full-length $23 \mathrm{~S}$ rRNA sequence data for phylogenetic analysis were obtained from PCR-amplified segments that supplemented data previously obtained (Everett \& Andersen, 1997). Two PCR primers were used for these amplifications: primer $6 \mathrm{~F}$ matching the coding strand of the Chlamydia 23S rRNA (5' GGATGAGTTGTGAATAGG $3^{\prime}$ ) and a complementary primer that PCR amplifies the 5S gene of Brucella abortus ( $5^{\prime}$ AGTTCGGGATGGGATCGGGTG $3^{\prime}$ ). Additional primers were used to sequence both the PCR products and the cloned PCR-product templates. PCR conditions for all amplifications using AmpliTaq DNA polymerase (Perkin Elmer) were $30 \mathrm{~s}$ at $94{ }^{\circ} \mathrm{C}, 15 \mathrm{~s}$ annealing, $30 \mathrm{~s}$ at $72{ }^{\circ} \mathrm{C}$ in the GeneAmp PCR System 9600 thermal cycler (Perkin Elmer). Annealing temperatures were specific for each primer set. The $3^{\prime}$ end of each $\sim 3000$ bp 23S rRNA gene was determined by FoldRNA analysis of sequence data for the intergenic spacer that had been spliced, by computer, to sequence data for a 200 base segment of $23 \mathrm{~S}$ rRNA extending into the $5 \mathrm{~S}$ gene. The $5^{\prime}$ end of the $23 \mathrm{~S}$ rRNA genes in $6 \mathrm{BC}^{\mathrm{T}}$, $\mathrm{NJ} 1$ and R22 had previously been identified by primer extension analysis (Everett \& Andersen, 1997).

For phylogenetic analysis, full-length $16 \mathrm{~S}$ rRNA and $23 \mathrm{~S}$ rRNA data were aligned using CLUSTAL w (Thompson et al., 1994). There were several short segments in the $23 \mathrm{~S}$ rRNA which were difficult to align, however, the results are robust with respect to alternative alignment decisions and also to the removal of these segments. The $3^{\prime}$ ends of both genes were trimmed to produce sequences of even length: $1558 \mathrm{nt}$ positions were analysed for the 16S rRNA gene and $2956 \mathrm{nt}$ positions were analysed for the 23S rRNA gene. Phylogenetic trees were generated using the maximum-parsimony and neighbour-joining routines of PAUP 4.0.0d63 (Swofford, 1993). PAUP's heuristic search parameters were set to trunk-bisection-resection branch swapping with no limit on the number of trees held per run, and with branches having a maximum length of zero collapsed to yield polytomies. Branching order reliability was evaluated by 1000 replications of bootstrap resampling using parsimony (Felsenstein, 1985). Trees were also constructed using the maximum-likelihood routine DNAML of PHYLIP $3.5 \mathrm{c}$ (Felsenstein, 1993). Parsimony and maximum-likelihood trees were both generated using 10 replicate runs in which the input sequences were read in random order. Saturation plots were constructed contrasting phyletic versus pairwise distances for each tree. Non-linearity of these plots would suggest that excessive homoplasy could be responsible for nodes being joined at random rather than due to similarity (Vuillaumier et al., 1997).

Signature sequence identification. 'Signature sequence' segments were identified by examining chlamydial $16 \mathrm{~S}$ rRNA gene sequences and partial chlamydial 23S rRNA gene segments, most of which are currently in the GenBank database. Signature segments were narrowly defined regions of sequence that were conserved and distinctive for each of nine groups. The $16 \mathrm{~S}$ signature segments were determined from the 59 discrete chlamydial 16S rRNA genes in GenBank plus the Chlamydia pneumoniae Koala sequence from strain Con. There were $\geqslant 5$ representative strains from six of the nine groups in the Chlamydiaceae and fewer strains in the other groups. The partial 23S rRNA sequences used to identify the $23 \mathrm{~S}$ signature sequence included $>50$ strains, with $\geqslant 5$ representative strains from each of five of the nine groups in the Chlamydiaceae and fewer strains in the other groups. The 298 base $16 \mathrm{~S}$ signature sequence could be PCR-amplified and sequenced using $51{ }^{\circ} \mathrm{C}$ annealing and primers which matched all chlamydiae: $16 \mathrm{SIGF}\left(5^{\prime}\right.$ CGGCGTGGATGAGGCAT 3'), which matched the 16S rRNA gene at position 40, and 16SIGR (5' TCAGTCCCAGTGTTGGC $3^{\prime}$ ), which complemented the 16S rRNA gene at position 337 (E. coli and Chlamydia numbering). The rDNA template was PCR amplified with AmpliTaq DNA polymerase as described above. In some cases, the rRNA template was reverse transcribed and PCR was performed in a single reaction mix using the GeneAmp EZ rTth RNA PCR Kit (Perkin Elmer). PCR products were filtered with Microcon 100 microconcentrators (Amicon) prior to sequencing.

The $23 \mathrm{~S}$ signature sequence, which was domain I of the $23 \mathrm{~S}$ rRNA gene, was PCR-amplified and partially sequenced using either or both of two strategies. The first strategy was applied to reverse-transcribed rRNA or to rDNA template to amplify a $600 \mathrm{bp}$ PCR product containing most of the signature sequence. This strategy used two conserved bacterial primers, U23F (5' GATGCCTTGGCATTGATAGGCGATGAAGGA $3^{\prime}$ ) and 23SIGR (5' TGGCTCATCATGCAAAAGGCA $3^{\prime}$ ) (annealing temperature $61^{\circ} \mathrm{C}$ ), which can also amplify non-chlamydial rRNAs. These primers were used in direct sequence analysis of PCR products that were filtered with Microcon 100 microconcentrators. For the Chlamydiaceae strains, a second strategy was also used to characterize the $23 \mathrm{~S}$ signature sequence. A $1 \mathrm{kbp}$ product was PCR-amplified from rDNA template using primers 16SF2 (5' CCGCCCGTCACATCATGG $\left.3^{\prime}\right)$ and 23SIGR ( $5^{\prime}$ TGGCTCATCATGCAAAAGGCA $3^{\prime}$ ). This amplicon contained a complete $627 \mathrm{bp}$ domain I segment, the $\geqslant 220 \mathrm{bp}$ intergenic spacer, and $150 \mathrm{bp}$ of the $16 \mathrm{~S}$ rRNA gene; domain I was fully sequenced using primers $16 \mathrm{SF} 2$, 23SIGR, IGSIGF (5' ATAATAATAGACGTTTAAGA $\left.3^{\prime}\right)$ and 23R (5' TACTAAGATGTTTCAGTTC 3').

PFGE. DNA plugs of $1 \%(\mathrm{w} / \mathrm{v})$ low-melting-point agarose that contained Renografin-purified chlamydiae were prepared for PFGE. Pellets of chlamydiae and chlamydiaeinfected cells were resuspended in $40 \%(\mathrm{w} / \mathrm{v})$ Renografin (Solvay Animal Health) in PBS containing $\mathrm{Ca}^{2+}$ and $\mathrm{Mg}^{2+}$ (Sambrook et al., 1989), incubated for $10 \mathrm{~min}$ at room temperature, and diluted in at least 2 vols PBS. Lysed hostcell DNA was sheared by repeated pipetting. Chlamydiae were then pelleted at 10000 r.p.m., resuspended in a few microlitres of PBS, mixed with $1 \%$ LMP agarose at $37^{\circ} \mathrm{C}$, and cooled in aliquots in a plug mould (Bio-Rad Laboratories). After refrigeration, the plugs were sequentially incubated in several buffers: $50 \mathrm{mM}$ DTT, $30 \mathrm{mM}$ Tris, $10 \mathrm{mM}$ EDTA pH 9.0 at $37^{\circ} \mathrm{C}$ overnight; $10 \mathrm{mM}$ Tris, $10 \mathrm{mM}$ EDTA pH 8.0 (TE) with DNase-free RNase (Boehringer Mannheim) at $37^{\circ} \mathrm{C}$ for $5 \mathrm{~h}$; TE containing $10 \mu \mathrm{g}$ Proteinase $\mathrm{K} \mathrm{ml}^{-1}$ (Gibco BRL Life Technologies) at $50{ }^{\circ} \mathrm{C}$ overnight; and TE at $4{ }^{\circ} \mathrm{C}$, with four or more changes of TE over a period of a week or more.

Intitially, the plugs were subjected to $4 \mathrm{krad}$ (40 gray) of gamma irradiation (Walker et al., 1991) to linearize chromosome prior to electrophoresis. Chromosome from treated and untreated plugs, however, showed no reproducible differences in electrophoretic mobility. Subsequently, there- 
fore, radiation treatment was removed from the protocol. The plugs were inserted into a $1 \%(\mathrm{w} / \mathrm{v})$ agarose gel $(12.5 \times 12.5 \times 1.2 \mathrm{~cm})$ and electrophoresed at $150 \mathrm{~V}, 14^{\circ} \mathrm{C}$ using the CHEF-DR Drive Module, Pulsewave 760, and power supply model $200 / 2.0$ (Bio-Rad) with recirculating buffer containing $22.5 \mathrm{mM}$ Tris/borate, $1 \mathrm{mM}$ EDTA. A puise time of $2 \mathrm{~min}$ was applied for $24 \mathrm{~h}$, the buffer was replaced with fresh buffer, then a pulse time of 4 min was applied for $30 \mathrm{~h}$ (Bergthorsson \& Ochman, 1995). Gels were stained with Sybr Green I nucleic acid stain (FMC BioProducts) (not shown) or with ethidium bromide. PFGE II size markers (Boehringer Mannheim) were used.

Southern blot analysis. An oligonucleotide primer recognizing the origin of replication of all known chlamydial plasmids was synthesized. This 102 base primer consisted of four direct repeats with a restriction site at each end (Integrated DNA Technologies): GCGGCCGC[TTGCAACT(T/C)T(T/A)GGTGGTAGACT $]_{4}$ CCCGGG. The primer was $5^{\prime}$ end-labelled with $\left[\gamma^{32} \mathrm{P}\right] \mathrm{ATP}[\mathrm{ICN} ; 10 \mu \mathrm{Ci}$ $\mu l^{-1}\left(3.7 \times 10^{5} \mathrm{~Bq}^{-1}\right), 4500 \mathrm{Ci} \mathrm{mol}{ }^{-3}\left(1.665 \times 10^{14} \mathrm{~Bq}\right.$ $\mathrm{mol}^{-4}$ )] using T4 polynucleotide kinase (GibcoBRL Life Technologies). The $25 \mu$ labelling reaction was stopped by the addition of $75 \mu 1 \mathrm{H}_{2} 0$ and $50 \mu 17.5 \mathrm{M}$ ammonium acetate. Labelled primer was precipitated by adding $5 \mu \mathrm{l} 5 \mathrm{mg}$ tRNA $\mathrm{ml}^{-1}$ in $\mathrm{H}_{2} 0$, then adding $450 \mu \mathrm{l} 95 \%$ ethanol, followed by centrifugation. Chlamydial DNA that was embedded in agarose plugs (above) was separated by standard electrophoresis in $1 \times$ TBE on $1 \%(\mathrm{w} / \mathrm{v})$ agarose gels $(10 \times 6.5 \mathrm{~cm}$, or $10 \times 14 \mathrm{~cm})$. A DNA size standard, $1 \mathrm{~kb}$ DNA Ladder (GibcoBRL Life Technologies), was electrophoresed at the same time. After electrophoresis, the separated DNAs were denatured by soaking the gel for $45 \mathrm{~min}$ in several vols of $1.5 \mathrm{M} \mathrm{NaCl}, 0.5 \mathrm{M} \mathrm{NaOH}$ at $4{ }^{\circ} \mathrm{C}$; neutralized in $1 \mathrm{M}$ Tris pH 7.2, 1.5 M NaCl (Sambrook et al., 1989); transferred to a Hybond-N + nucleic acid transfer membrane (Amersham Life Science) by capillary transfer in $10 \times \operatorname{SSC}(0.15 \mathrm{M}$ sodium citrate, $1.5 \mathrm{M} \mathrm{NaCl} \mathrm{pH} \mathrm{7.0),} \mathrm{and} \mathrm{baked} \mathrm{onto} \mathrm{the}$ membrane at $80^{\circ} \mathrm{C}$, ambient pressure for $2 \mathrm{~h}$. The blot was prehybridized and then hybridized with probe at $60{ }^{\circ} \mathrm{C}$ overnight in $6 \times \mathrm{SSC}$ containing $0.1 \%(\mathrm{w} / \mathrm{v})$ SDS and sheared denatured calf thymus DNA $\left(100 \mu \mathrm{g} \mathrm{ml}^{-1}\right)$. The blot was washed at $60{ }^{\circ} \mathrm{C}$ in $1.0 \times$ SSC, $0.5 \%$ SDS and then washed repeatedly at $50{ }^{\circ} \mathrm{C}$ in $0.1 \times \mathrm{SSC}, 0.5 \% \mathrm{SDS}$ prior to autoradiography.

\section{RESULTS}

\section{Phylogenetic analysis of 165 rRNA revealed nine groups in two lineages in the Chlamydiaceae}

Ninety-three 16S rRNA sequences available from the Chlamydiaceae, 'Candidatus Parachlamydia' and 'Simkania' in GenBank, as of March 1998, were aligned with new data for SFPD and for WSU 861044. The alignment required few gaps, so no positions needed to be removed from the analysis. This large dataset contained a number of clusters of sequences that were so closely related as to be nearly identical. Phylogenetic trees were constructed using a subset of 23 of the 93 sequences, chosen so that all clusters were represented but so that nearly identical sequences were removed. Parsimony, maximum-likelihood (MLE) and neighbour-joining (NJ) algorithms were used to determine phylogenetic relationships among the 23 sequences.
Parsimony analysis found 28 different mostparsimonious trees, each requiring 693 nucleotide substitutions. Only 272 of these substitutions were within the Chlamydiaceae lineage. A consensus tree was constructed using a $50 \%$ majority rule. This tree had a consistency index of $0.75(1.0$ being the highest possible), indicating a lack of resolution at several nodes. Elimination of the outgroups resulted in 26 equally parsimonious trees and only increased the consistency index to $0 \cdot 77$, indicating that the distance of the outgroups was not responsible for there being more than one most parsimonious tree. The low consistency index was also not due to mutational saturation, because a plot of pairwise versus phyletic differences for all groups was linear. The MLE and NJ trees were similar to several of the parsimony trees, the differences being at nodes that were poorly resolved in the parsimony analysis. In particular, the NJ tree had a monophyletic clade containing feline, abortion, avian and $C$. pecorum clusters. This clade shared a common ancestor with $C$. pneumoniae, while the parsimony and MLE trees had C. pecorum paired with $C$. pneumoniae. The finding of more than one most parsimonious tree was due primarily to the presence of several nodes that were determined by a small number of nucleotide substitutions.

The MLE, NJ and parsimony trees were all in agreement with two observations: the same nine sequence clusters were always present in every tree and the $C$. trachomatis-like clusters were separated into a distinct, well-supported lineage. Eight of the nine specific clusters were the human strains of $C$. trachomatis, swine strains of $C$. trachomatis, $C$. trachomatis strains that infect Muridae species, $C$. pneumoniae strains, $C$. pecorum strains, feline strains, abortion strains and avian strains. The ninth, guinea pig strain GPIC, was the single representative of its group. The order in which GPIC diverged from the feline, abortion and $C$. psittaci clusters was unresolved. The parsimony and NJ trees showed GPIC diverging between the feline cluster and C. psittaci, while the MLE tree made GPIC a sister group with the abortion cluster.

Bootstrap analysis, in which 1000 replicate trees were produced using random subsamples of the nucleotide positions in the dataset, was used to assess statistical support for the individual branches (Fig. 1). In the non- $C$. trachomatis-like group, the B577 and EBA abortion strains were always grouped together, although they formed a monophyletic clade distinct from the avian cluster in only $55 \%$ of the bootstrap replicates. Thus, the abortion strains were closely related to each other but as a group had not yet diverged very far from the avian strains. A clade that contained feline, guinea pig, avian and abortion clusters was present in $98 \%$ of the trees. The bootstrap procedure provided $99 \%$ support for the monophyly of the C. trachomatis-like clusters, but little support for any particular order of divergence among the human, swine and Muridae clusters within C. trachomatis.

Sixty-eight per cent of the bootstrap replicates showed 


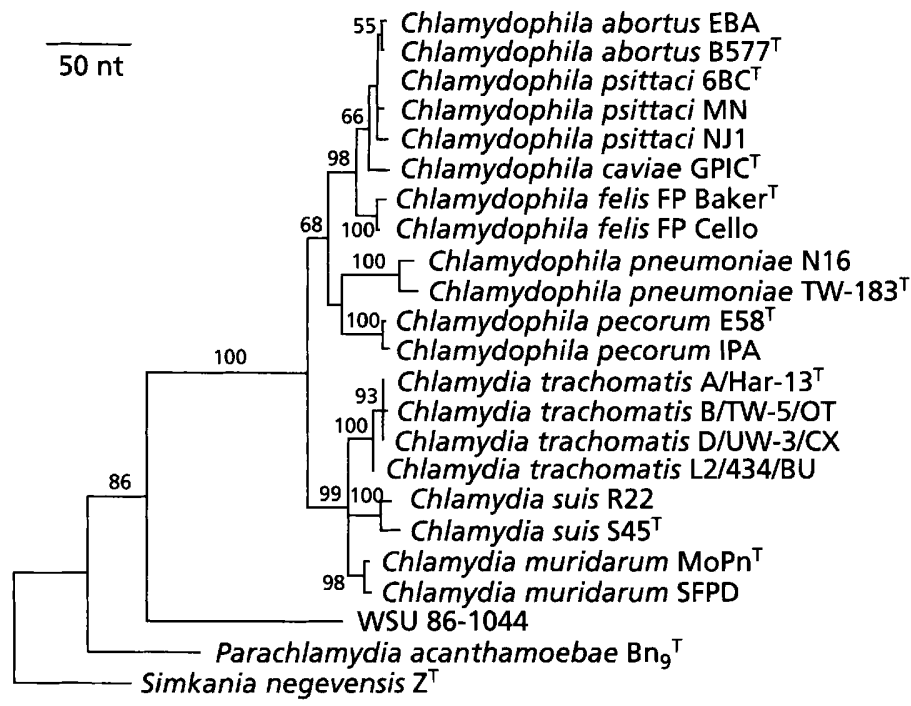

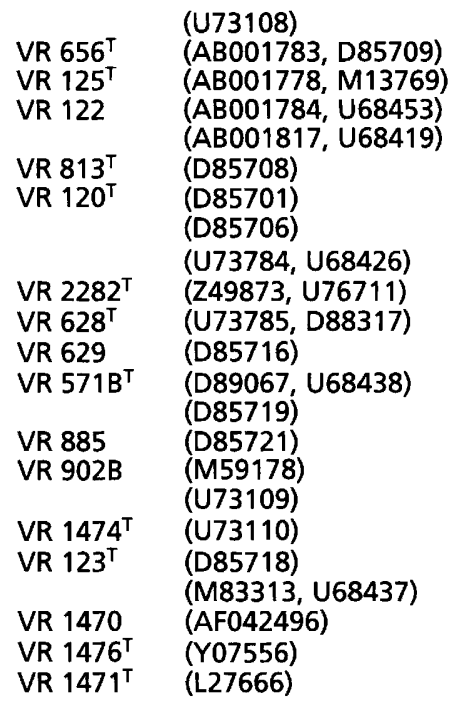

Fig. 1. Phylogeny of the order Chlamydiales, constructed using full-length $16 \mathrm{~S}$ rRNA genes. Branch lengths are measured in nucleotide substitutions. Numbers show the percentage of times each branch was found in 1000 bootstrap replicates. Branches without bootstrap values occurred in less than $50 \%$ of the trees. Values in parentheses are the GenBank sequence accession numbers.

Table 2. Percentage differences among the $16 \mathrm{~S}$ rRNA genes of Chlamydiales spp. type strains and some of their closest relatives

Chlamydia type strains are $\mathrm{MoPn}^{\mathrm{T}}, \mathrm{A} / \mathrm{Har}-13^{\mathrm{T}}$ and $\mathrm{S} 45^{\mathrm{T}}$. Chlamydophila type strains are $\mathrm{B}^{2} 77^{\mathrm{T}}, 6 \mathrm{BC}^{\mathrm{T}}, \mathrm{GPIC}^{\mathrm{T}}$, FP Baker ${ }^{\mathrm{T}}$, E58 ${ }^{\mathrm{T}}$ and $\mathrm{TW}-183^{\mathrm{T}}$. A consensus sequence (Ccon) was derived from these genes to identify a reference strain that contained the highest proportion of conserved $16 \mathrm{~S}$ sequence motifs for the family Chlamydiaceae. Ccon is heavily weighted toward the Chlamydiaceae lineage because plurality for the consensus was 6, and all nine Chlamydiaceae type strains were included in the identification of Ccon. Percentages are to the nearest whole integer $( \pm 0.5 \%)$ or to the nearest decimal $( \pm 0.05 \%)$ (Jukes \& Cantor, 1969).

\begin{tabular}{|c|c|c|c|c|c|c|c|c|c|c|c|c|c|c|c|c|}
\hline & 17 & 16 & 15 & 14 & 13 & 12 & 11 & 10 & 9 & 8 & $\tau$ & 6 & 5 & 4 & 3 & 2 \\
\hline $1 \mathrm{Ccon}$ & 1.9 & $2 \cdot 0$ & $2 \cdot 0$ & $2 \cdot 4$ & $3 \cdot 2$ & $4 \cdot 2$ & $3 \cdot 1$ & 3.7 & $4 \cdot 2$ & $13 \cdot 0$ & $16 \cdot 2$ & $16 \cdot 3$ & $30 \cdot 9$ & $31 \cdot 2$ & $33 \cdot 3$ & 33.4 \\
\hline 2 Planctomycetes staleyi & 36 & 35 & 36 & 36 & 35 & 35 & 35 & 35 & 34 & 33 & 37 & 35 & 37 & 35 & 15 & 0 \\
\hline 3 Pirellula marina & 36 & 35 & 36 & 36 & 35 & 35 & 35 & 35 & 35 & 34 & 37 & 35 & 39 & 33 & 0 & \\
\hline 4 Verrucomicrobium VeGlc2 & 33 & 33 & 33 & 33 & 33 & 33 & 33 & 33 & 33 & 31 & 33 & 33 & 37 & 0 & & \\
\hline 5 Chloroplast Chlorella ellipsoidea & 32 & 32 & 32 & 33 & 32 & 32 & 32 & 31 & 31 & 34 & 35 & 35 & 0 & & & \\
\hline 6 Simkania & 18 & 18 & 18 & 18 & 18 & 18 & 18 & 18 & 18 & 13 & 18 & 0 & & & & \\
\hline 7 WSU $86-1044$ & 18 & 18 & 18 & 18 & 18 & 18 & 18 & 18 & 18 & 14 & 0 & & & & & \\
\hline 8 Parachlamydia & 15 & 15 & 14 & 15 & 14 & 14 & 14 & 15 & 14 & 0 & & & & & & \\
\hline $9 \mathrm{S4} 5^{\mathrm{T}}$ & 6 & 6 & 6 & 6 & 5 & 7 & 2 & 3 & 0 & & & & & & & \\
\hline $10 \mathrm{~A} / \mathrm{Har}-13^{\mathrm{T}}$ & 5 & 5 & 5 & 5 & 5 & 6 & 2 & 0 & & & & & & & & \\
\hline $11 \mathrm{MoPn}^{\mathrm{T}}$ & 4 & 4 & 4 & 5 & 5 & 6 & 0 & & & & & & & & & \\
\hline $12 \mathrm{TW}-183^{\mathrm{T}}$ & 4 & 4 & 5 & 5 & 4 & 0 & & & & & & & & & & \\
\hline $13 \mathrm{E}^{2} 8^{\mathrm{T}}$ & 4 & 4 & 4 & 4 & 0 & & & & & & & & & & & \\
\hline 14 FP Baker $^{\mathrm{T}}$ & 2 & 2 & 2 & 0 & & & & & & & & & & & & \\
\hline $15 \mathrm{GPIC}^{\mathrm{T}}$ & 1 & 1 & 0 & & & & & & & & & & & & & \\
\hline $166 \mathrm{BC}^{\mathrm{T}}$ & $0 \cdot 2$ & 0 & & & & & & & & & & & & & & \\
\hline $17 \mathrm{~B} 577^{\mathrm{T}}$ & 0 & & & & & & & & & & & & & & & \\
\hline Accession no. & D85709 & M13769 & D85708 & D85701 & D88317 & L06108 & D85718 & D89067 & U73110 & $Y 07556$ & 5 AF042496 & $L 27666$ & $\times 12742$ & $\mathrm{X} 99390$ & $\mathrm{X} 62912$ & M34126 \\
\hline
\end{tabular}

the Chlamydiaceae splitting at its base into two monophyletic clades: the $C$. trachomatis-like group and a clade containing the rest of the Chlamydiaceae clusters. This pattern represents the most probable structure for the root of the Chlamydiaceae because the next most likely split, between $C$. pneumoniae and all other Chlamydiaceae, had only $31 \%$ bootstrap support. The clade containing just $C$. pecorum and $C$. pneumoniae in the Fig. 1 bootstrap tree, which also appeared in the MLE tree, had only $44 \%$ support. It was not conclusive whether $C$. pecorum, $C$. pneumoniae or their common ancestor, diverged first from the $C$. trachomatis-like group. The order of divergence at the base of the Chlamydiaceae tree was most likely the $C$. trachomatis-like clusters first, then $C$. pneumoniae and C. pecorum groups followed by the feline, guinea pig, avian and abortion groups.

The non-C. trachomatis-like 16S rRNA gene sequences varied $\leqslant 5 \%$ among themselves. The $C$. trachomatis- 
Table 3. Percentage differences among 235 rRNA genes of Chlamydiales spp. strains and some of their closest relatives

Percentages are to the nearest whole integer $( \pm 0.5 \%)$ or to the nearest decimal $( \pm 0.01 \%)$ (Jukes \& Cantor, 1969). MoPn and SFPD are $0.03 \%$ different and have identical percentage differences with all strains as shown. $\mathrm{NJ} 1$ and $6 \mathrm{BC}$ are $0 \cdot 37 \%$ different and have identical percentage differences with all Chlamydiaceae strains as shown.

\begin{tabular}{|c|c|c|c|c|c|c|c|c|c|c|c|c|c|}
\hline & 13 & 12 & 11 & 10 & 9 & 8 & 7 & 6 & 5 & 4 & 3 & 2 & 1 \\
\hline 1 Chloroplast Chiorella ellipsoidea & 48 & 48 & 47 & 48 & 48 & 47 & 48 & 48 & 49 & 48 & 48 & 49 & 0 \\
\hline 2 Simkania & 18 & 18 & 19 & 19 & 20 & 19 & 18 & 18 & 19 & 15 & 18 & 0 & \\
\hline 3 WSU 86-1044 & 19 & 19 & 19 & 19 & 19 & 19 & 18 & 19 & 18 & 15 & 0 & & \\
\hline 4 Parachlamydia & 17 & 17 & 18 & 18 & 19 & 18 & 17 & 18 & 18 & 0 & & & \\
\hline $5 \mathrm{R} 22$ & 8 & 8 & 8 & 8 & 9 & 8 & 2 & 2 & 0 & & & & \\
\hline $6 \mathrm{~L} 2 / 434 / \mathrm{BU}$ & 8 & 8 & 8 & 8 & 9 & 8 & 2 & 0 & & & & & \\
\hline $7 \mathrm{MoPn}^{\mathrm{T}}$ & 7 & 7 & 7 & 8 & 8 & 7 & 0 & & & & & & \\
\hline $8 \mathrm{TW}-183^{\mathrm{T}}$ & 3 & 3 & 3 & 3 & 4 & 0 & & & & & & & \\
\hline 9 IPA & 4 & 4 & 5 & 5 & 0 & & & & & & & & \\
\hline 10 FP Baker ${ }^{T}$ & 2 & 2 & 2 & 0 & & & & & & & & & \\
\hline $11 \mathrm{GPIC}^{\mathrm{T}}$ & 2 & 2 & 0 & & & & & & & & & & \\
\hline $126 \mathrm{BC}^{\mathrm{T}}$ & $0 \cdot 7$ & 0 & & & & & & & & & & & \\
\hline 13 EBA & 0 & & & & & & & & & & & & \\
\hline Accession no. & U76710 & U68447 & U68451 & U68457 & U68434 & U76711 & U68436 & U68443 & U68420 & Y07555 & AF042496 & U68460 & M36158 \\
\hline
\end{tabular}

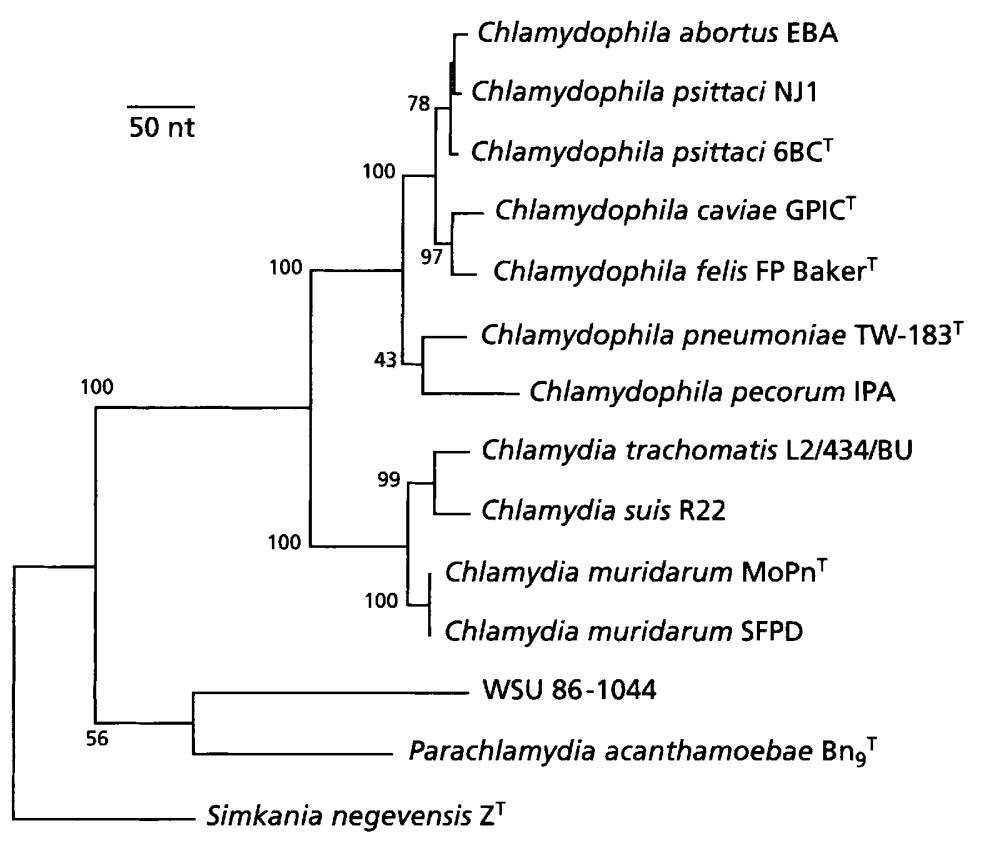

(U76710)

(U68419)

(U68447)

(U68451)

(U68457)

(U76711)

(U68434)

(U68443)

(U68420)

(U68436)

(U68437)

(AF042496)

(Y07555)

(U68460)

Fig. 2. Phylogeny of 14 members of the order Chlamydiales, constructed using full-length 235 rRNA genes. Branch lengths are measured in nucleotide substitutions. Numbers show the percentage of times each branch was found in 1000 bootstrap replicates. Branches without bootstrap values occurred in less than $50 \%$ of the trees. Values in parentheses are the GenBank sequence accession numbers.

like gene sequences varied $\leqslant 3 \%$ among themselves (Table 2). The non-C. trachomatis-like gene sequences were $4-7 \%$ different from the $C$. trachomatis-like genes. The 4-7\% differences were comparable to $16 \mathrm{~S}$ rRNA differences that separate a number of bacterial species and genera, as determined by BLAST searching of the GenBank database, and approached neither the near-zero difference limit for species discussed by Palys et al. (1997) nor the $80 \%$ identity limit proposed for the class Actinobacteria by Stackebrandt et al. (1997). The separation of these nine groups was also consistent with the phyletic separation of chlamydiae based on this gene (Fig. 1) and with biochemical and phenotypic differences between the groups. Thus, genetic differences in the 16S rRNA gene supported the proposed revision of species and genera in the Chlamydiaceae.

\section{$16 S$ reference sequence determined for the Chlamydiaceae}

To identify a $16 \mathrm{~S}$ rRNA sequence that could be used to specifically and easily recognize members of the Chlamydiaceae, a consensus sequence (Ccon) of rep- 


Chlamydia muridarum
Chlamydia trachomatis
Chlamydia suis
Chlamydophila felis
Chlamydophila abortus
Chlamydophila psittaci
Chlamydophila caviae
Chlamydophila pecorum
Chlamydophila pneumoniae
Consensus
Parachlamydia
Simkania
WSU86-1044

Chlamydia muridarum Chlamydia trachomatis Chlamydia suis

Chlamydophila felis

Chlamydophila abortus

Chlamydophila psittaci

Chlamydophila caviae

Chlamydophila pecorum

Chlamydophila pneumoniae

Consensus

Parachlamydia

Simkania

WSU86-1044

Chlamydia muridarum

Chlamydia trachomatis

Chlamydia suis

Chlamydophila felis

Chlamydophila abortus

Chlamydophila psittaci

Chlamydophila caviae

Chlamydophila pecorum

Chlamydophila pneumoniae

Consensus

Parachlamydia

Simkania

WSU86-1044
40

139

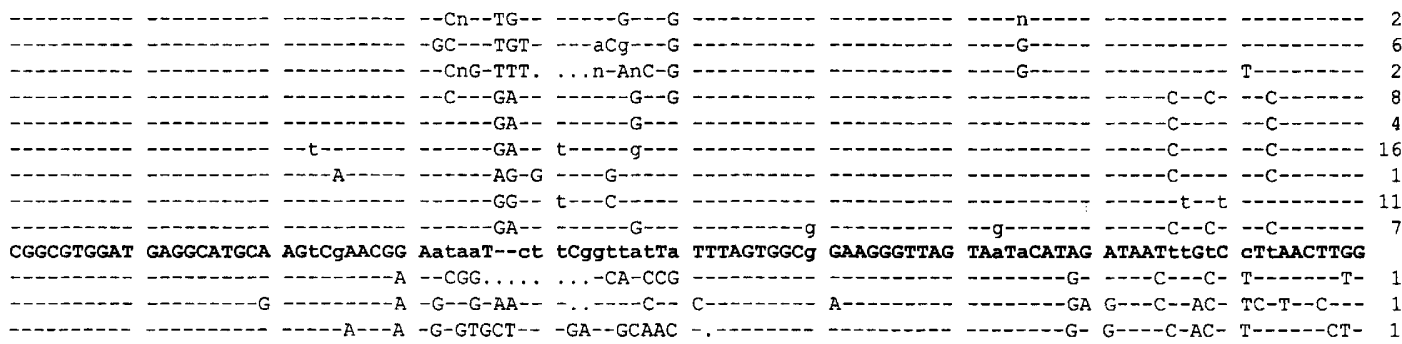

140

190

239

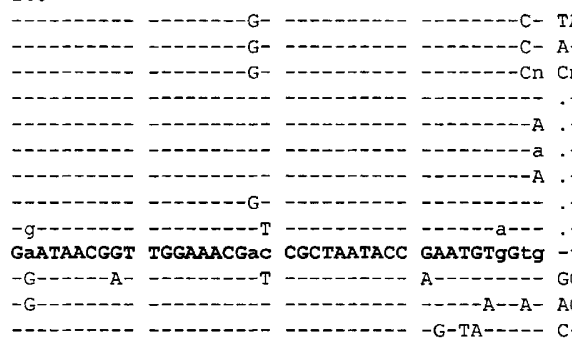

TA-A- $-\mathrm{A}-\mathrm{G}--$

-NT- CG

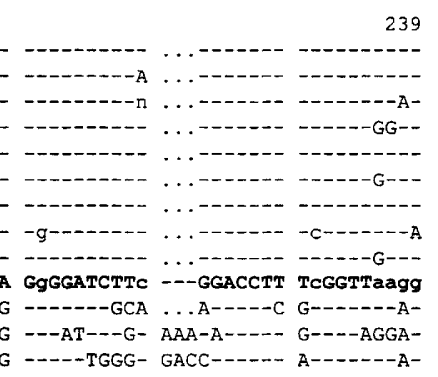

240

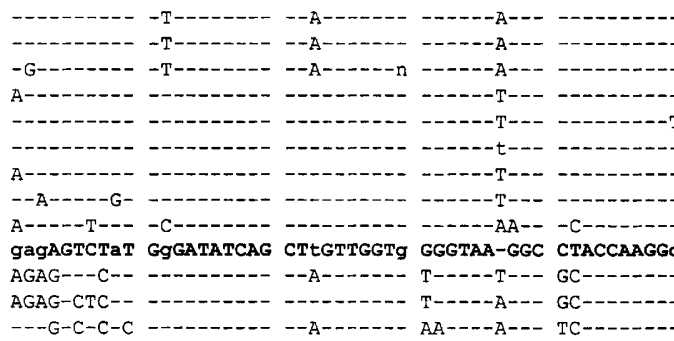

337

290

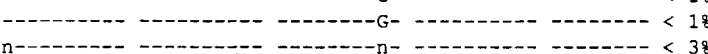

年

T-10 -

T-10-1- - -

$-\mathrm{T}-$

-

\begin{abstract}
Fig. 3. $16 \mathrm{~S}$ rRNA signature sequences for twelve species in the order Chlamydiales. The amplification/sequencing primers, 16SIGF ( $5^{\prime}$ CGGCGTGGATGAGGCAT $\left.3^{\prime}\right)$ and 16SIGR ( $5^{\prime}$ TCAGTCCCAGTGTTGGC $\left.3^{\prime}\right)\left(51^{\circ} \mathrm{C}\right.$ annealing temperature), match or complement the first and last 17 bases in this sequence, respectively. The Chlamydiaceae species lines: all strains in the species are identical (upper case), are identical and match the consensus line (-), or most but not all strains use the indicated nucleotide (lower case); $n=$ no consensus for that species; $()=$. alignment gap. Consensus line: all known Chlamydiaceae are identical (upper case), at least one strain of the Chlamydiaceae is not identical to the consensus nucleotide (lower case), or fewer than six species have the same base at this position (-). The number of strains used to compile the consensus for each species is appended to the end of the first lines of sequence. Base $\mathbf{4 0}$ is the position $\mathbf{4 0}$ in the $16 \mathrm{~S}$ rRNA gene of Chlamydiales and also $E$. coli. The percentage variation within each species signature is appended to the ends of the last lines of sequence. Dots were inserted into the sequences to improve alignment.
\end{abstract}

resentative 16S rRNA genes from diverse Chlamydia strains and from closely related bacteria was identified. The Ccon sequence represented a plurality $\geqslant 6$ identities at each position and matched the most conserved sequence data among these bacteria. A percentage difference analysis of Ccon with these groups was also carried out (Table 2). This comparison indicated that the $16 \mathrm{~S}$ rRNA sequence from $C$. psittaci B577 best matched a consensus of conserved Chlamydia sequences.

\section{Phylogenetic analysis of 235 rRNA revealed two major lineages within the Chlamydiaceae}

Thirteen complete Chlamydiales 23S rRNA gene sequences, including 11 Chlamydia strains, 'Simkania' $\mathrm{Z}$ and WSU 86-1044, were sequenced and compared to the previously reported 23S rRNA sequence of 'Candidatus Parachlamydia' (Amann et al., 1997). The
Chlamydia sequences differed from the outgroup sequences by $15-20 \%$ (Table 3 ). Parsimony analysis produced a single most parsimonious tree with 1380 nucleotide substitutions and a consistency index of 0.76 (Fig. 2). The MLE tree was identical to the parsimony tree and $C$. pecorum and $C$. pneumoniae were paired together. The NJ tree differed from this tree only in that it showed C. pecorum strain IPA to be more closely related to the outgroups than was $C$. pneumoniae TW-183.

The Chlamydiaceae 23S rRNA tree split at its base into two monophyletic lineages with $100 \%$ bootstrap support (Fig. 2). One lineage included the $C$. trachomatis-like strains and the other included the non- $C$. trachomatis-like strains. Among the $C$. trachomatis-like strains, the swine and human isolates separated from the Muridae isolates with almost $100 \%$ bootstrap support. The base of the non-C. trachomatis- 
like lineage was not well-defined: either $C$. pneumoniae or a common ancestor of $C$. pneumoniae and of $C$. pecorum could have been most closely related to the $C$. trachomatis-like clade. A monophyletic lineage containing the C. psittaci abortion/avian/feline/guinea pig strains formed the rest of the non-C. trachomatislike clade with $100 \%$ bootstrap support. A saturation plot of pairwise versus phyletic differences did not show evidence of mutational saturation; thus the low consistency index was due not to excessive homoplasy but to a lack of information needed to resolve some specific nodes (e.g. the $C$. pneumoniae $+C$. pecorum node and the WSU 86-1044 + 'Candidatus Parachlamydia' node).

The non- $C$. trachomatis-like 23S rRNA gene sequences varied $\leqslant 5 \%$ among themselves; the $C$. trachomatislike $23 \mathrm{~S}$ rRNA gene sequences varied $\leqslant 2 \%$ among themselves (Table 3). The non- $C$. trachomatis-like gene sequences were $7-9 \%$ different from the $C$. trachomatis-like genes. The 7-9\% gene sequence differences were comparable to $23 \mathrm{~S}$ rRNA differences that separate a number of bacterial genera, as determined by BLAST searching of the GenBank database. They were also consistent with the phyletic separation of groups in the Chlamydiaceae (Figs 1 and 2) and with biochemical and phenotypic differences between the groups. Thus, genetic differences in the $23 \mathrm{~S} \mathrm{rRNA}$ gene supported the proposed revision of species and genera in the Chlamydiaceae.

\section{Sequence signatures identified for the Chlamydiaceae groups}

Previously it was shown by sequence comparison that the $16 \mathrm{~S}-23 \mathrm{~S}$ ribosomal intergenic spacer is a defined region of sequence that is functionally conserved and distinctive for each of the nine chlamydial groups (Everett \& Andersen, 1997). A 'signature sequence' such as this can identify these groups for purposes of classification. Signature sequences were identified in the 16S and 23S rRNA genes of the Chlamydiaceae by aligning all of the ribosomal segments for chlamydial organisms that are in GenBank. The $16 \mathrm{~S}$ signature sequence started at base 40 in the gene and was 298 bases long (Fig. 3). The homologous 'Simkania', 'Candidatus Parachlamydia' and WSU 86-1044 sequences were also examined (Fig. 3). Confidence in the $16 \mathrm{~S}$ species signature was highest for human $C$. trachomatis strains, $C$. pneumoniae strains, C. pecorum strains, and $C$. psittaci feline, abortion and avian strains because $\geqslant 4$ sequences were available for each. Variation within the 16S signature consensus for any single species was $\leqslant 3 \%$. New data from $16 \mathrm{~S}$ signature sequence analysis of $C$. pneumoniae $\mathrm{N} 16$ and $C$. trachomatis SFPD were used to update N16 and SFPD sequences in GenBank and in Fig. 3.

The 23S signature sequence, which was domain I of this gene, started at base 1 in the gene and was 627 bases long (Fig. 4). The homologous 'Simkania' and
'Candidatus Parachlamydia' sequences were also examined (Fig. 4). Confidence in the 23S species signature was highest for human $C$. trachomatis strains, swine $C$. trachomatis-like strains, $C$. pneumoniae strains, $C$. pecorum strains and C.psittaci abortion and avian strains, because $\geqslant 5$ sequences were available for each. Variation within the domain I signature consensus for any single species was always $\leqslant 3 \%$, but usually $\leqslant 1 \%$ (Fig. 4 ).

\section{PFGE revealed conserved genome size in the Chlamydiaceae}

PFGE of agarose-embedded chlamydial DNA was employed to determine genome sizes for six groups in Chlamydia and to compare these sizes with 'Simkania' and $E$. coli. The data indicated that uncut chlamydial genome migrates at an approximate size of $1-1.2 \mathrm{Mbp}$ (Fig. 5). C. trachomatis strains and C. trachomatis-like swine strains had an apparent size of $1-1 \cdot 1 \mathrm{Mbp}$ and non-C. trachomatis strains had an apparent size of about $1.2 \mathrm{Mbp}$. This agreed with the size of the 1.045 Mbp C. trachomatis strain L2/434/BU genome identified by Birkelund \& Stephens (1992). Additional study of these genomes using restriction endonucleases will be needed to confirm the actual genome sizes.

\section{Extrachromosomal plasmids were strain- and group- specific}

To compile information that could contribute to a more complete description of groups in the Chlamydiaceae, chlamydial DNA was examined for the presence of an extrachromosomal plasmid. DNAs that had been prepared in agarose plugs for PFGE were separated by standard electrophoresis on $1 \%$ gels, were examined by ethidium bromide staining, and were Southern blotted using a probe that matched the plasmid origin of replication. A sharp band that stained only weakly with ethidium bromide hybridized strongly to the probe. The mobility of this band was markedly slower than the mobility of a band of sheared DNA that stained strongly with ethidium bromide. There was no hybridization of the probe to the sheared DNA. These bands were larger than the $12 \mathrm{kbp}$ DNA molecular size marker. A faint band with a mobility of $7.5 \mathrm{kbp}$ was only rarely detected with the probe on Southern blot. Handling of the chromosomal/plasmid preparations in liquid form (rather than in agarose plugs) greatly increased the amount of $7.5 \mathrm{kbp}$ plasmid detected by Southern blot and reduced the amount of detectable $>12 \mathrm{kbp}$ plasmid. The retarded mobility of the $>12 \mathrm{kbp}$ plasmid band was consistent with this band being an open circular form of the chlamydial plasmid (Levene \& Zimm, 1987) or with its being a dimer of interlinked circular forms, as have been previously reported.

The presence of plasmids was determined or confirmed in 14 strains (Table 4). The absence of plasmid was discovered or confirmed for six strains (Table 4). Strains were designated plasmid ${ }^{-}$only if a genomic 
(a)

Chlamydia muridarum Chlamydia trachomatis Chlamydica suis

Chlamydephila felis

Chlamydophila abortus

Chlamydophila psittaci

Chlamydophila caviae

Chlamydophila pecorum

Chlamydophila pneumonia

Consensus

Parachlamydia

Simkania

WSU86-1044

Chlamydia muridarum

Chlamydia trachomatis

Chlamydia suis

Chlamydophila felis

Chlamydophila aborms

Chlamydophila psittaci

Chlamydophila caviae

Chlamydophila pecorum

Chlamydophila pneumoni

Consensus

Parachlamydia

Simkania

WSU86-1044

Chlamycia muridarum

Chlamydia murachomatis

Chlamydia suis

Chlamydia suis
Chlamydophila felis

Chlamydophila abortu

Chlamydlophila psittaci

Chlamydophila coviate

Chlamydophila peconum

Chlamydophila pneumonia

Consensus

Parachlamydia

Simkania

WSU86-1044

Chlamydia muridarum

Chlamydia trachomatis

Chlamydia suis

Chlamydophila felis

Chlamydophila abortus

Chlamydophila psittaci

Chlamydophila caviae

Chlamydophila pecorum

Chlamydophila pmeumonia

Consensus

Parachlamydia

Simkania

WSU86-1044

Chlamydia muridarum

Chlamydia trachomatis

Chlamydia trach

Chlamydia suis

Chlamydophila abortus

Chlamydophila psittaci

Chlamydophila caviae

Chlamydophila pecorum

Chlamydophila pneumonia

Consensus

Parachlamydia

Simkania

WSU86-1044

Chlamydia muridarum

Chlamydia truchomatis

Chlamydia suis

Chlamydophila felis

Chlamydophila aborrus

Chlamydophila psittaci

Chlamydophila caviae

Chlamydophila pecorum

Chlamyedophila pneumonio

Consensus

Parachlamydia

Simkania

WSU86-1044
1

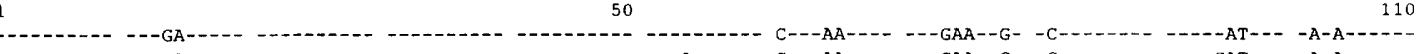
-1
-

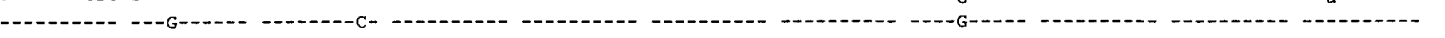

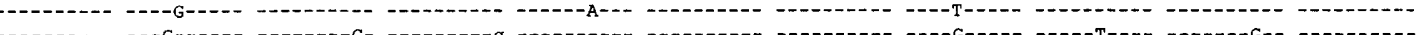
TACAGACCAA GTTatTAAGA GCTATTGGtG GATGCCTTGg CATTGACAGg CGAtGAAGGA tGCgttTACC TGCa-tAatC TtCGGcGAGC TGGTataaAg CtatGACCCG ATTT-GT--- -C - - - - - G ---GC---- - -TT-TGTT- - - 111 160

(11

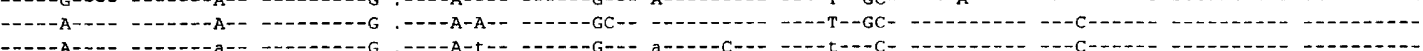
-

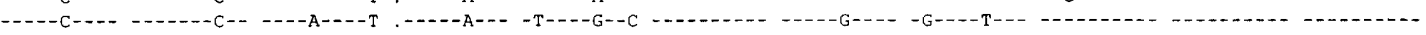
-

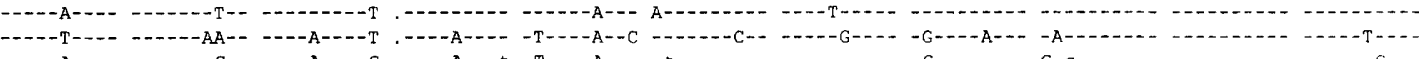

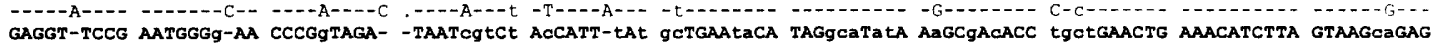

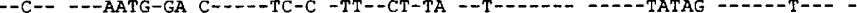

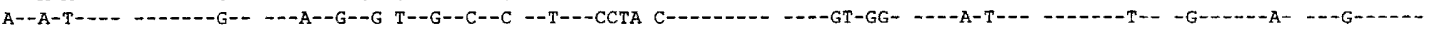

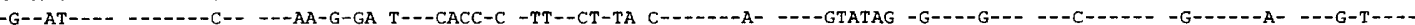
221

- - G-. - G-. -G- . - - -1 GAAAgAAAT CAA.AGAGAT TCCCTgagTa GCGGCGAGCG AAAgGGGAa- AGoCCAAACC a-atttttaa --tgtGGGG TGTAGggTcG ataacatggG ATCttaAgTt GAAAAgAAAT CAA.AGAGAT TCCCTgaGTA GCGGCGAGCG AAAgGGGAa- AGCCCAAACC a-atttttaa --tgtGGGGT TGTAGGgTCG ataacatggG ATCttaAgTt 331

380

440

C-1 - - -

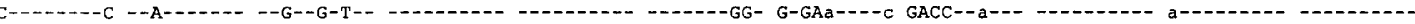
$\begin{array}{llll}- & \end{array}$ -

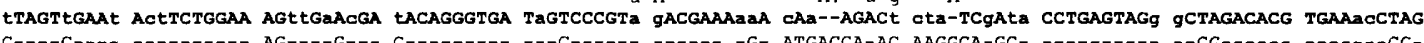

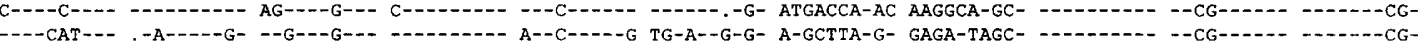

4418990650

-

-

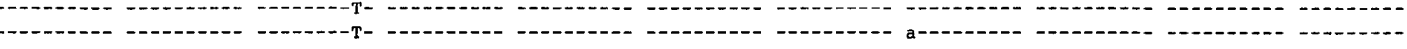

T-1

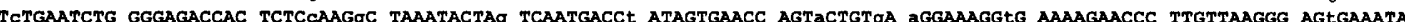
$\begin{array}{llll} & \end{array}$ 551 600 650

- - -1
0 AACCTGAA C

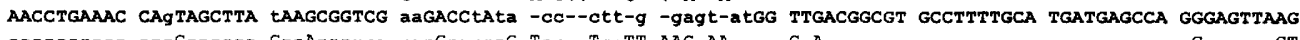

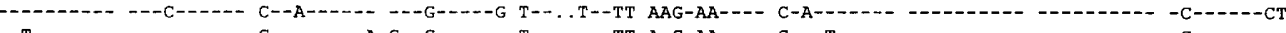
- T-

Fig. 4. For legend see facing page. 
(b)

$1 \mathrm{~kb}$

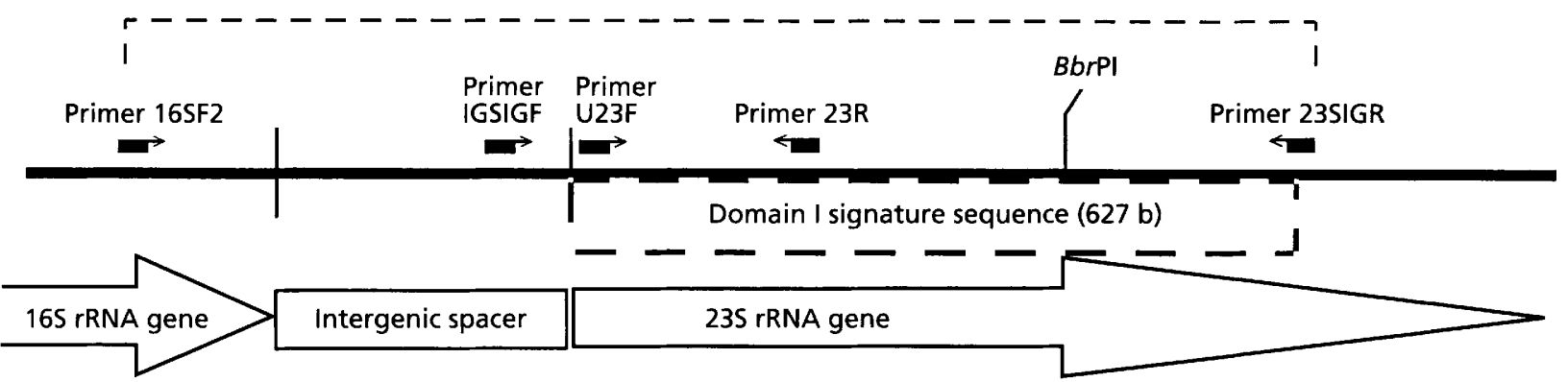

Fig. 4. 235 domain I rRNA signature sequences for eleven species in the order Chlamydiales. This segment could be PCR amplified using an annealing temperature of $61^{\circ} \mathrm{C}$ and amplification/sequencing primers U23F (5' GATGCCTTGGCATTGATAGGCGATGAAGGA 3') (bases 31-60) and 23SIGR (5' TGGCTCATCATGCAAAAGGCA 3') (extending 13 bases past base 627). (a) Chlamydiaceae species lines: all strains in the species are identical (upper case), are identical and match the consensus line $(-)$, or most but not all strains use the indicated nucleotide (lower case); $()=$. alignment gap. Consensus line: all known Chlamydiaceae are identical (upper case), at least one strain of the Chlamydiaceae is not identical to the consensus nucleotide (lower case), or fewer than six species have the same base at this position (-). The number of strains used to compile the consensus for each species is appended to the end of the first lines of sequence. Base 1 is the first nucleotide of the 235 rRNA gene, based on primer extension analysis (Everett \& Andersen, 1997). The percentage variation within each species signature is appended to the ends of the last lines of sequence. Dots were inserted into the sequences to improve alignment. (b) Map of the domain I signature sequence in the 235 rRNA gene. Primers 16SF2, U23F and 23SIGR recognize all members of the Chlamydiales. Primers IGSIGF and 23R are specific for the Chlamydiaceae.

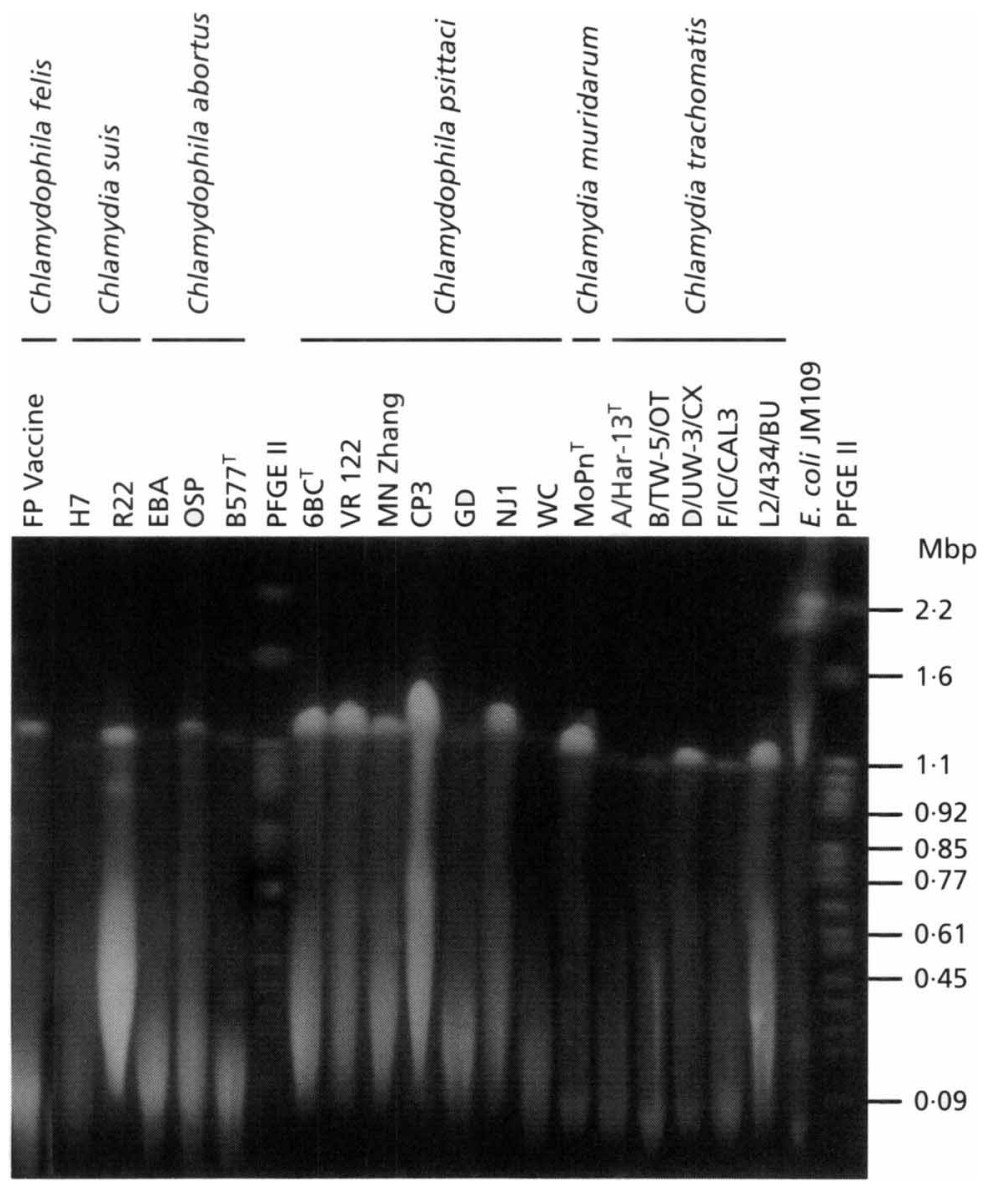

Fig. 5. PFGE of chlamydial chromosomes. Linearized chromosomes migrated at 1.0 1.2 Mbp. E. coli JM109 chromosome was included as a control. 
Table 4. Presence or absence of exrachromosomal plasmid in selected strains of Chlamydia and Chlamydophila spp.

Compiled from Farencena et al. (1997); Girjes et al. (1988); Grayston et al. (1989); Joseph et al. (1986); Lusher et al. (1989); Peterson et al. (1990); Thomas et al. (1997); and Timms et al. (1988). Strains in bold were identified or confirmed in this study.

\begin{tabular}{|c|c|c|}
\hline Species & Present & Absent \\
\hline Chlamydia trachomatis & $\begin{array}{l}\text { A/Har-13 }{ }^{\mathrm{T}}, \mathbf{D} / \mathrm{UW}-3 / \mathrm{CX}, \mathbf{B} / \mathrm{TW}-5 / \mathrm{OT} \\
\text { F/IC/CAL3, L1/440/LN, L2/434/BU }\end{array}$ & $\begin{array}{l}\text { L2 }\left(\mathrm{pCT}^{-}\right) ; \mathrm{Ba}\left(\mathrm{pCT}^{-}\right) \text {; GTS-3, GTS- 10, } \\
\text { GTS-17, GTS-18, GTS-21, GTS-23, } \\
\text { GTS-31, GTS-36, GTS-39* }\end{array}$ \\
\hline Chlamydia suis & $\mathbf{S}^{\mathrm{T}}{ }^{\mathrm{T}}, \mathbf{R} 22, \mathbf{R} 24, \mathbf{R} 27, \mathbf{H} 7$ & - \\
\hline Chlamydia muridarum & $\mathrm{MoPn}^{\mathrm{T}}$ & - \\
\hline Chlamydophila caviae & GPIC $^{T}$ & - \\
\hline Chlamydophila felis & Cello, Pring & FP BakerT, FP Vaccine \\
\hline Chlamydophila psittaci & $\begin{array}{l}\text { 6BC }^{\mathrm{T}}, \mathbf{A 2 4}, \text { M56, MN Zhang, N352, } \\
\text { RA1/56 gull, } 360 \text { duck }\end{array}$ & MN VR-122 \\
\hline Chlamydophila abortus $\dagger$ & - & B5777, EBA, OSP, A22, S26, \\
\hline Chlamydophila pneumoniae & N16 & TW-183' ${ }^{\mathrm{T}}$ Koala I, IOL-207 \\
\hline Chlamydophila pecorum & $\mathbf{E 5 8}^{\mathrm{T}}$, Koala II & - \\
\hline
\end{tabular}

* Forty University of Massachusetts Medical Center Chlamydia trachomatis isolates from sexually transmitted disease (STD) or pelvic inflammatory disease (ID) patients were grown and characterized; nine were plasmid minus (An \& Olive, 1994; An et al., 1992).

$\dagger$ A. Rodolakis, personal communication.

Table 5. Taxa in the order Chlamydiales

Source information is provided where possible. Biovar reference strains may be obtained from ATCC or from the original sources.

\begin{tabular}{|c|c|c|}
\hline \multirow[t]{2}{*}{ Taxon } & \multicolumn{2}{|c|}{ Type/reference strain } \\
\hline & Name & ATCC no. \\
\hline \multicolumn{3}{|l|}{ Family I: Chlamydiaceae } \\
\hline Chlamydia muridarum sp. nov. & $\mathrm{MoPn}^{\mathrm{T}}$ & VR $123^{\mathrm{T}}$ \\
\hline Chlamydia suis sp. nov. & $\mathrm{S} 45^{\mathrm{T}}$ & VR $1474^{\mathrm{T}}$ \\
\hline Chlamydia trachomatis & $\mathrm{A} / \mathrm{Har}-13^{\mathrm{T}}$ & VR $571 \mathrm{~B}^{\mathrm{T}}$ \\
\hline Biovar trachoma & $\mathrm{C} / \mathrm{PK}-2$ & 1 \\
\hline Biovar LGV & $\mathrm{L} 2 / 434 / \mathrm{BU}$ & VR 902B \\
\hline Chlamydophila abortus sp. nov. & $\mathrm{B} 577^{\mathrm{T}}$ & VR $656^{\mathrm{T}}$ \\
\hline Chlamydophila caviae sp. nov. & GPIC $^{\mathrm{T}}$ & VR $813^{\mathrm{T}}$ \\
\hline Chlamydophila felis sp. nov. & FP Baker ${ }^{T}$ & VR $120^{\mathrm{T}}$ \\
\hline Chlamydophila pecorum comb. nov. & E58 ${ }^{\mathrm{T}}$ & VR $628^{\mathrm{T}}$ \\
\hline Chlamydophila pneumoniae comb. nov. & TW-183 ${ }^{\mathrm{T} *}$ & VR $2282^{\mathrm{T}}$ \\
\hline Biovar TWAR & TW-183 & VR 2282 \\
\hline Biovar Koala & LPCon & \\
\hline Biovar Equine & N16 & \\
\hline Chlamydophila psittaci comb. nov. & $6 \mathrm{BC}^{\mathrm{T}}$ & VR $125^{\mathrm{T}}$ \\
\hline \multicolumn{3}{|l|}{ Family II: Simkaniaceae fam. nov. } \\
\hline Simkania negevensis sp. nov. & $\mathrm{Z}^{\mathrm{T}}$ & VR $1471^{\mathrm{T}}$ \\
\hline \multicolumn{3}{|l|}{ Family III: Parachlamydiaceae fam. nov. } \\
\hline Parachlamydia acanthamoebae sp. nov. & $\mathrm{Bn}_{9}{ }^{\mathrm{T}}$ & VR $1476^{\mathrm{T}}$ \\
\hline Family IV: & WSU 86-1044 & VR 1470 \\
\hline
\end{tabular}

${ }^{*} \mathrm{TW}-183^{\mathrm{T}}$ is also available through the Washington Research Foundation, $1107 \mathrm{NE}$ 45th St, Suite 205, Seattle, WA 98105, USA (Tel: +1 206633 3569; Fax: + 1206633 2981; WWW URL: http://www.halcyon.com/lori/wrf.htm). 
band was detected by PFGE and no plasmids were detected by Southern blot analysis.

\section{DISCUSSION}

\section{Identification of coherent groupings in Chlamydiales: ribosomal evidence}

We propose a reclassification of groups in the order Chlamydiales based on 16S rRNA sequence similarity clusters, on concurrence between analyses of fulllength 16S and 23S rDNA data for all known groups, and on supporting evidence showing these groups to be phenotypically and ecologically differentiated (Palys et al., 1997). Some of these groups are wellcharacterized (see descriptions, below), while others have only recently been identified and phenotypic studies are under way. Ecological differentiation of groups is evident by the often host-related variations in virulence, morphology, propagation and chronic maintenance. According to this proposal, members of the order Chlamydiales are obligately intracellular bacteria that have the chlamydia-like developmental cycle of replication and that have $>80 \%$ rDNA sequence identity with chlamydial $16 \mathrm{~S}$ rRNA genes and / or 23S rRNA genes (Figs 1 and 2, Tables 2 and 3). This order includes strains belonging to the Chlamydiaceae, strains closely related to 'Candidatus Parachlamydia acanthamoebae', 'Simkania' strain Z and strain WSU 86-1044. This proposal separates these groups at the family level. Actual rRNA gene differences between these groups were $13-20 \%$, and between other bacterial lineages this range of differences can typically separate classes, orders or families. The Chlamydiaceae is a well-characterized family and all strains have $>90 \%$ rRNA identity. Among 16S rRNA sequences in the Chlamydiaceae, strain B577 has diverged less than all others from 'Ccon', a chlamydial consensus sequence (Table 2). Therefore, to be identified as a member of the Chlamydiaceae, the 16S rRNA gene of a new chlamydia-like isolate should have $>90 \%$ identity with the 16S rRNA gene of B577 (accession no. D85709).

Analysis of the rooted, $1558 \mathrm{nt} 16 \mathrm{~S}$ rRNA dataset supported two specific conclusions. The first major conclusion was that nine sequence clusters were present in the Chlamydiaceae. These clusters were present in all phylogenetic trees and were independent of the algorithms used to construct the trees. These groupings agreed with many phenotypic and ecological differences among chlamydial groups, including antigenicity, associated disease, host range and genomic endonuclease restriction (Everett \& Andersen, 1997). They were also in agreement with observations by Herring (1993) that these groupings would provide an 'outline for a new taxonomy of chlamydial species'. Genetic studies of the Chlamydiaceae have shown patterns of relatedness that were consistent with these clusters (Carter et al., 1991; Everett \& Andersen, 1997; Fitch et al., 1993; Glassick et al., 1996; Kaltenboeck et al., 1993; Löbau et al., 1995; Pettersson et al., 1997; Pudjiatmoko et al., 1997; Storey et al., 1993; Takahashi et al., 1997; Zhang et al., 1993). The 16S rRNA tree failed to show strong genetic divergence between the EBA/B577 abortion cluster and the avian cluster, from which the abortion group is evolving. However, the abortion cluster was well-supported by DNA-DNA reassociation (Table 1), by the intriguing absence of plasmids from all known isolates (Table 4) and by virulence studies (Jorgensen, 1997; Page, 1967; Rodolakis et al., 1989).

The second major conclusion derived from the $16 \mathrm{~S}$ rRNA analysis was that the $C$. trachomatis-like group diverged before other groups in the Chlamydiaceae. There was $99 \%$ support for the monophyly of the $C$. trachomatis-like group and $68 \%$ support for the early divergence of this group (Fig. 1). This conclusion was possible because of the unambiguous rooting provided by the 'Candidatus Parachlamydia', 'Simkania' and WSU 86-1044 genes. Problems in rooting the Chlamydiaceae and in determining relationships within the Chlamydiaceae have been ongoing since 1986, when ribosomal data were first obtained for chlamydiae (Weisburg et al., 1986). Most recently, Pettersson et al. (1997) used eight ribosomal sequences from 'Simkania', 'Candidatus Parachlamydia' and more distantly related bacteria to root a set of nine chlamydial sequences. However, because of difficulty in aligning the chlamydial sequences to the distant outgroups, $22 \%$ of the $16 \mathrm{~S}$ rRNA sequence positions contained gaps and on this basis were removed from their analysis. Their resulting phylogeny had little support in our analyses, which used complete gene sequences.

Analysis of the 23S rRNA showed $100 \%$ support for the early divergence of $C$. trachomatis-like strains in the Chlamydiaceae (Fig. 2). The 23S rRNA phylogeny was in complete agreement with the most probable $16 \mathrm{~S}$ rRNA phylogeny. Separation of lineages was greatest and bootstrap support was strongest, using the $23 \mathrm{~S}$ rRNA data.

\section{Evolution of coherent clusters in Chlamydiales}

Recent discoveries of chlamydiae in amoebae (Amann et al., 1997; Birtles et al., 1997; Gautom et al., 1996) suggest the possibility that chlamydial parasites radiated from single-celled eukaryotes into multicelled hosts. This radiation would have been accompanied by intense selective pressure in animal hosts. This selective pressure may have influenced the evolution of all of the proposed groupings in Chlamydiales, because members of all of the families have been associated with infection of vertebrates (Birtles et al., 1997; Dilbeck et al., 1990; Kahane et al., 1999; Moulder, 1991). Intense selective pressure is consistent with the large differences seen between the rRNAs of the proposed families. Between some Chlamydiaceae groups, however, branching order was affected by relatively small numbers of nucleotide substitutions in 
the rRNA, although there were large DNA-DNA reassociation differences (Table 1). (In Figs 1 and 2 such branches had the weakest bootstrap support or the branching orders were shown as unresolved.) This suggests that intense selective pressures did not always involve the rRNA. An unusually low rate of rDNA change could very likely be due to the inability of the replicating chlamydiae to survive the extracellular environment or to infect new host cells. Propagation of changes in rRNA sequence and in ribosome function can take place in chlamydiae only if mutants remain in step with the replication cycle of the total population in the inclusion; other mutants may not survive host cell lysis or may not be able to compete successfully for new host cells in chronically infected hosts.

\section{Evidence for the early divergence of the C. trachomatis-like group}

The strong ribosomal evidence for early divergence of the monophyletic $C$. trachomatis-like group in the Chlamydiaceae was supported by other data: genome size (Fig. 5), glycogen production only by the $C$. trachomatis-like strains (Moulder, 1991; Rogers et al., 1996), ompA sequence analysis (Kaltenboeck et al., 1993), and conservation of epitopes deduced from the omp $A$ sequences of $C$. trachomatis-like strains (see descriptions below). Genome size among the $C$. trachomatis-like strains was smaller than among the non-C. trachomatis-like strains (Fig. 5). These sizes were consistent with recent determinations of genome size for specific isolates: the 1.2 Mbp size seen in Fig. 5 for non- $C$. trachomatis-like strains was close to the 1230025 bp genome size of $C$. pneumoniae (GENSET, 1997). The 1.1 Mbp size for $C$. trachomatis $\mathrm{L} 2 / 434 / \mathrm{BU}$ and D/UW-3/CX in Fig. 5 corresponded to a mapped size of $1.045 \mathrm{Mbp}$ (Birkelund \& Stephens, 1992) and to genome sizes of $1038680 \mathrm{bp}$ (GENSET, 1997) and 1042519 bp (Stephens et al., 1998), respectively. Glycogen production by bacteria has been shown to be correlated with the management of nutrient deprivation (Sakamoto \& Bryant, 1998). Thus, it is possible that a gene which was normally essential during nutrient deprivation was lost by genetic deletion in the formation of the $C$. trachomatis-like lineage.

\section{Evidence for ecologically coherent clusters}

At least two of the proposed families have evolved specific ecological niches: the Chlamydiaceae are primarily vertebrate pathogens and strains in the 'Candidatus Parachlamydia' group appear to reside primarily in amoebae. Ecologically coherent clusters can be identified by DNA-DNA reassociation (Palys et al., 1997). DNA-DNA reassociation analysis of the Chlamydiaceae showed groupings that were congruent with the nine groups identified using $16 \mathrm{~S}$ and $23 \mathrm{~S}$ rRNA data (Table 1). The range of DNA-DNA reassociation similarity among the groups in the Chlamydiaceae was 1-100\%. Within C. pecorum and
C. pneumoniae the ranges were $88-100 \%$. In the current $C$. psittaci, however, the range was much broader $(20-85 \%)$ because it contained four of the groups separated by ribosomal clustering. The two $C$. trachomatis-like groups that have been characterized were $20-65 \%$ similar by DNA-DNA reassociation. Both the $C$. psittaci and the $C$. trachomatis ranges were sufficiently broad that they could each encompass new species: the value established for the discrimination of species is $70 \%$ and for the discrimination of genera is about 20\% (Amann et al., 1995; Schleifer \& Stackebrandt, 1983; Wayne et al., 1987). Therefore, DNA-DNA reassociation provided good evidence that the ribosomal clusters were ecologically distinct groups.

DNA-DNA reassociation is a difficult technique to apply to the measurement of relatedness among intracellular bacteria, however. Values are affected not only by genetic distance but also by the presence of diverse host DNAs, multicopy extrachromosomal DNAs (Brenner \& Falkow, 1971), strain integrity, and methodology. Some of these influences are evident in the available DNA reassociation data for chlamydiae. For example, $C$. psittaci $\mathrm{B} 577$ has been reported to have similarities of 34 and $85 \%$ versus $C$. psittaci $6 \mathrm{BC}^{\mathrm{T}}$; B577 has reported similarities of 27 and $46 \%$ with C. psittaci Cal-10 MN (Fukushi \& Hirai, 1989) (Table 1). Such wide variances in chlamydial data indicate that DNA-DNA reassociation is not the method of choice for conclusively determining relatedness among chlamydial populations.

Other evidence also contributes to the suggestion that the Chlamydiaceae is made up of a number of ecologically distinct populations. An ecologically distinct population can typically occur when one group outgrows others in a particular niche. It has been observed that most chlamydial isolations produce single serovars, rather than mixed populations and that most Chlamydia groups have specific host or disease associations. Thus, apparently, long-term adaptation between chlamydiae and animal species has contributed to the evolution of ecologically distinct populations. The apparent host ranges are fairly narrow. For example, one group of $C$. trachomatis-like chlamydiae has been isolated only from swine, some $C$. trachomatis-like strains and the TWAR serovar of $C$. pneumoniae are found exclusively in humans. $C$. pecorum has been isolated only from mammals. Some C. psittaci strains are primarily isolated from birds; one group primarily infects cats. Another group is associated with colonization of the placenta, abortion and weak neonates. Disease and host associations have been used for years to help restrict the probable identity of chlamydial agents. However, the condition of the host or the presence of other bacteria or viruses can also play a role in the severity of chlamydial disease and may lead to inappropriate conclusions about the virulence of isolates. In addition, apparently host-specific strains can be made to cause disease in experimentally infected animals (Page, 1967) and 
Chlamydia strains that infect birds have caused sporadic disease in mammals and tortoises. Thus, although host and disease associations are not definitive markers for purposes of classification, they are consistent with the ecological separation of these populations.

\section{Variable traits in Chlamydiaceae}

Some data assembled in this study contributed to descriptions of groups but proved to be inappropriate for primary group separations. Specifically, these data included plasmid ${ }^{-}$and plasmid ${ }^{+}$genotypes, which could be found in most groups (Table 4) and resistance to sulfadiazine, which interferes with folate synthesis. Sulfadiazine resistance appears to characterize many of the lineages in Chlamydiales, although this has not been widely published. Some strains that are known to be resistant include $C$. pecorum IPA and $\mathrm{E} 58^{\mathrm{T}}, C$. pneumoniae AR-39, C. psittaci FP Baker, GPIC, VS1, CP3, MN, B577 (A. A. Andersen, unpublished; B. Kaltenböck, unpublished), C. trachomatis-like swine strains (Andersen \& Rogers, 1998) and 'Simkania'. C. trachomatis-like isolates from humans and Muridae are sensitive to sulfadiazine, however (Fox et al., 1993; Moulder et al., 1984). Furthermore, both resistance and sensitivity in apparently isogenic $C$. psittaci $6 \mathrm{BC}$ strains has been reported (Lin \& Moulder, 1966). Fan et al. (1992) determined that sulfadiazine-resistant and sulfadiazine-sensitive chlamydiae synthesize folates but vary in their ability to transport host folates. Fan et al. (1992) concluded that chlamydial synthesis and transport of folate is in a transitional stage of evolution and probably varies from one strain of Chlamydia to the next. For these reasons, it is inappropriate to use sulfadiazine resistance as a phyletic marker for chlamydiae.

The observations described in this report are consistent with the presence of two genera and nine species in the Chlamydiaceae, as distinguished by genetic, phenotypic and ecologic differences. We found that ribosomal sequence data could be used to easily assign isolates to these groups and to also distinguish families within the Chlamydiales.

\section{Emended description of the order Chlamydiales}

We emend the description of the order Chlamydiales to include obligately intracellular bacteria that have a chlamydia-like developmental cycle of replication, Gram-negative or Gram-positive infectious EBs (elementary bodies), $>80 \% 16 \mathrm{~S}$ rRNA gene sequence identity), and/or $>80 \%$ 23S rRNA gene sequence identity with Chlamydiales spp. Currently, the order Chlamydiales includes the families Chlamydiaceae and Simkaniaceae, which have Gram-negative EBs, and Parachlamydiaceae, which has variable Gram staining of EBs. The EB form has an inner and an outer membrane and a variable periplasmic space. EBs are round, highly electron-dense, $0 \cdot 2-0.6 \mu \mathrm{m}$ in diameter, and metabolically inactive. The chlamydial cycle of replication is initiated when EBs are endocytosed by eukaryotic cells. During this stage, EBs reside within cytoplasmic inclusions where they differentiate by enlarging to $0 \cdot 6-1.5 \mu \mathrm{m}$, becoming less electron-dense RBs (reticulate bodies), and undergoing binary fission. Inclusions are unique vacuoles that do not undergo acidification or lysosomal fusion. Inclusions that have been studied in detail do not correspond to canonical endocytic vesicles, being essentially dissociated from the endocytic pathway and having some similarities with recycling endosomes (Hackstadt et al., 1997; van Ooij et al., 1997; Taraska et al., 1996). Over a period of days, RBs condense into EBs and chlamydiae are released by host cell rupture or by fusion of the inclusion membrane with the host cell plasma membrane. No alternate host vector is required. Many species of Chlamydiales coexist in an asymptomatic state within specific hosts, and it is widely believed that these hosts provide a natural reservoir for these species. The type genus for Chlamydiales is Chlamydia.

\section{Emended description of the family Chlamydiaceae}

The family Chlamydiaceae was previously described by Rake (1957). In accordance with rRNA analyses and corroborating sequence data, the emended family Chlamydiaceae is divided into two genera. Rules $39 \mathrm{a}$ and $39 \mathrm{~b}$ of the International Code of Nomenclature of Bacteria state that when a genus is subdivided, the original generic name must be retained by the genus containing the original type species (Lapage et al., 1992). Therefore, the genus name Chlamydia must remain with Chlamydia trachomatis, which contains $\mathrm{A} / \mathrm{Har}-13^{\mathrm{T}}$, the original type strain. A new name, Chlamydophila, has been coined for the genus containing non-Chlamydia trachomatis-like species and strains.

The family Chlamydiaceae includes current members of the order Chlamydiales that have $<10 \%$ overall $16 \mathrm{~S}$ rRNA gene diversity, $<10 \%$ overall $23 \mathrm{~S}$ rRNA gene diversity, a genome size of 1.0-1.24 Mbp, either one or two ribosomal operons in each genome, no tRNA in the 16S-23S intergenic spacer, little or no muramic acid, and the antigenic LPS trisaccharide $\alpha \mathrm{Kdo}-(2 \rightarrow 8)-\alpha \mathrm{Kdo}-(2 \rightarrow 4)-\alpha \mathrm{Kdo}$. The $\mathrm{G}+\mathrm{C}$ content for the Chlamydiaceae spp. is about $40 \%$ : $42.7 \pm 1.4 \mathrm{~mol} \%$ according to Moulder et al. (1984) and $40.5 \pm 1.5 \mathrm{~mol} \%$ according to Cox et al. (1988), using thermal denaturation methods; $39.5 \pm 0.3 \mathrm{~mol} \%$ according to Fukushi \& Hirai (1992) using an HPLC method. Among the nearly $10016 \mathrm{~S}$ rRNA genes that have been analysed for the Chlamydiaceae, the gene from strain B577 is most similar to a consensus sequence for the family (Table 3 ). Therefore, to be identified as a member of the Chlamydiaceae, the $16 \mathrm{~S}$ rRNA gene of a new chlamydia-like isolate should have $>90 \%$ identity with the 16S rRNA gene of B577 (accession no. D85709). The Chlamydiaceae are Gramnegative. Host-cell ATP is known to be required by some strains of $C$. psittaci and C. trachomatis, and may possibly be a requirement for all members of this family. The extracellular osmotic stability of the 
Chlamydiaceae EBs is maintained by a complex of disulfide-cross-linked envelope proteins. These include a major outer-membrane protein (MOMP; translation product of $o m p A$ ) with a molecular mass of $40 \mathrm{kDa}$, a hydrophilic cysteine-rich $60 \mathrm{kDa}$ protein, and a lowmolecular-mass cysteine-rich bacterial lipoprotein. When chlamydiae infect cells, the disulfide cross-links within and among these envelope proteins become chemically reduced, allowing transformation of EBs into RBs. Penicillin binding studies and genetic analyses indicate that at least some of the genes that are required for the synthesis of peptidoglycan are present in the chlamydial genome. However, chlamydiae do not contain muramic acid, indicating that chlamydial cell walls do not contain significant amounts of peptidoglycan. The bright flickering appearance, varying in intensity and duration, that is seen in chlamydiae-filled inclusions using visible light microscopy, suggests some degree of bacterial motility for strains of $C$. trachomatis, $C$. trachomatis-like swine strains, $C$. psittaci strains FP Baker, $6 \mathrm{BC}^{\mathrm{T}}$, VS1, CP3 and B577, and C. pecorum strain IPA (A. A. Andersen, unpublished data). Many, but not all, members of the Chlamydiaceae possess an extrachromosomal plasmid of about $7.5 \mathrm{kbp}$ (Table 4). These plasmids exhibit $60-80 \%$ interspecies conservation of sequence (Thomas et al., 1997), and shared features suggest that these plasmids have a monophyletic origin. These shared features include the conserved organization of eight open reading frames and an iteron in the origin of replication, which may regulate plasmid copy number (Nordström, 1990; Thomas et al., 1997). The iteron consists of four highly conserved tandem repeats. Plasmid copy number in some strains may also be regulated by antisense RNA (Nordström, 1990; Thomas et al., 1997).

The family Chlamydiaceae is distinguished from Simkaniaceae by $16 \mathrm{~S}$ rRNA sequence differences $(18.6 \pm 0.1 \%), \quad 23 \mathrm{~S}$ rRNA sequence differences $(18.6 \pm 0.3 \%)$, and by the absence of detectable Chlamydiaceae-specific Kdo trisaccharide antigen in 'Simkania' using a family-specific mAb (Kahane et al., 1999). The Chlamydiaceae spp. are distinguished from 'Candidatus Parachlamydia' by $16 \mathrm{~S}$ rRNA sequence differences $(14.9 \pm 0.7 \%), \quad 23 \mathrm{~S}$ rRNA sequence differences $(17.7 \pm 0.5 \%)$, and by the variable responses of 'Candidatus Parachlamydia' EBs to Gram staining (Amann et al., 1997; R. J. Birtles, personal communication). Members of the Chlamydiaceae can be readily identified and differentiated by signature sequence analysis (Figs 3 and 4). The type genus for the family Chlamydiaceae is Chlamydia.

\section{Emended description of the genus Chlamydia, including specific human, hamster, mouse and swine isolates}

The genus Chlamydia previously included all known chlamydiae (Moulder, 1984). As emended, Chlamydia is one of two genera in the Chlamydiaceae and includes
Chlamydia trachomatis, Chlamydia muridarum gen. nov., sp. nov. and Chlamydia suis gen. nov., sp. nov. The previous species, Chlamydia pecorum, Chlamydia pneumoniae and Chlamydia psittaci, have been transferred to the genus Chlamydophila. The complete $16 \mathrm{~S}$ and 23S rRNA gene sequences of Chlamydia species that have thus far been examined are each $\geqslant 97 \%$ identical. To be included in this genus, $16 \mathrm{~S}$ or $23 \mathrm{~S}$ rRNA sequences of new isolates should be $\geqslant 95 \%$ identical to the type strain, A/Har $13^{\mathrm{T}}$. Chlamydia species are readily identified and distinguished from other species by signature sequences (Figs 3 and 4) or by any of several other genes. Glycogen is produced by Chlamydia species and has been characterized by Garrett (1975). Glycogen is easily detected in the human Chlamydia trachomatis serovars and is detectable to varying degrees in Chlamydia muridarum and Chlamydia suis. The Chlamydia genomes characterized thus far are $1 \cdot 0-1 \cdot 1 \mathrm{Mbp}$, somewhat smaller than Chlamydophila genomes (Fig. 5). Chlamydia genomes examined thus far have two identical ribosomal operons (Engel \& Ganem, 1987; Everett \& Andersen, 1997; Fukushi \& Hirai, 1993; Scieux et al., 1992). The majority of strains in this genus have extrachromosomal plasmids, but not all (Table 4). Chlamydia strains have varying inclusion morphology and varying sensitivity to sulfadiazine. The currently known strains in Chlamydia have an epitope in MOMP that matches the core epitopes NPTI, TLNPTI, LNPTIA or LNPTI, recognized by vs4 Chlamydia trachomatis mAbs (see descriptions below) (Batteiger et al., 1996). The type species for the genus Chlamydia is Chlamydia trachomatis.

\section{Emended description of Chlamydia trachomatis}

Chlamydia trachomatis, as previously described (Moulder et al., 1984), comprised two human biovars and a murine biovar. As emended, only strains from the human biovars of Chlamydia trachomatis are being retained in Chlamydia trachomatis. Therefore, according to Rule $40 \mathrm{~b}$ of the International Code of Nomenclature of Bacteria, the original Chlamydia trachomatis epithet is retained by the group of human strains which contain $\mathrm{A} / \mathrm{Har} 3^{\mathrm{T}}$, the original type strain (Lapage et al., 1992). As emended, Chlamydia trachomatis strains have a high degree of sequence conservation. The Chlamydia trachomatis 16S rRNA genes that have been sequenced to date differ by $<$ $0.65 \%$. Chlamydia species are readily identified and distinguished from other species by ribosomal signature sequences (Figs 3 and 4) or by inspection of the 16S-23S intergenic spacer (Everett \& Andersen, 1997). Any of several other gene sequences may also be used to identify Chlamydia trachomatis. In particular, the gene for the MOMP, ompA (ompl), is widely used to distinguish Chlamydia trachomatis strains. Many, but not all, Chlamydia trachomatis strains have the extrachromosomal plasmid, pCT (Table 4). Glycogen accumulation by Chlamydia trachomatis is readily detected with iodine staining of inclusions. Chlamydia 
trachomatis strains are generally sensitive to sulfadiazine and tetracyclines. Most strains of Chlamydia trachomatis are recognized by $\mathrm{mAbs}$ to vs 4 core epitopes NPTI, TLNPTI, LNPTIA and LNPTI in MOMP (Batteiger et al., 1996; Peterson et al., 1991). Chlamydia trachomatis causes trachoma, sexually transmitted disease, some forms of arthritis, and neonatal inclusion conjunctivitis and pneumonia. The type strain for Chlamydia trachomatis is A/Har- $13^{\mathrm{T}}$ $\left(=\right.$ ATCC VR $\left.571 \mathrm{~B}^{\mathrm{T}}\right)$.

The 18 serovars of Chlamydia trachomatis are clustered into two biovars: trachoma and lymphogranuloma venereum (LGV) (Batteiger, 1996; Moulder et al., 1984). These serovars are recognized by specific mAbs and can be distinguished by ompA sequence differences. Worldwide, each serovar has only a minor amount of diversity, according to omp $A$ sequence analysis. The trachoma biovar currently has 14 serovars designated by the letters $\mathrm{A}$ through $\mathrm{K}$, plus $\mathrm{Ba}, \mathrm{Da}$ and Ia. Infection is limited primarily to squamocolumnar cells of mucous membranes. Serovars A-C are primarily associated with endemic trachoma and serovars D-K with sexually transmitted infection. The LGV biovar consists of four serovars, L1, L2, L2a and L3. LGV serovars are sexually transmitted and can invade lymphatic tissue. There is a clear separation of these biovars based on pathogenicity and on growth in cell culture and in laboratory animals. However, there is not a clear molecular pattern of separation of the LGV biovar from the trachoma biovar. Antigenic analyses of MOMP and sequence analyses of the $\operatorname{omp} A$ gene that expresses MOMP suggest that $\mathrm{L} 1$ and $\mathrm{L} 2$ are closely related to the B- and E- trachoma serovars and that L3 is related to the A-, C- and H-trachoma serovars (Fitch et al., 1993). Analyses of the extrachromosomal plasmid and of the gene for the $60 \mathrm{kDa}$ cysteine-rich protein, however, indicate that the LGV serovars are similar and that they differ from serovar B. The $16 \mathrm{~S}$ rRNA sequences of serovars $\mathrm{A}, \mathrm{B}$ and $\mathrm{D}$ are closer to each other than they are to the serovar L2 sequence. The $k d t A$ sequences in the trachoma biovar, including serovars $\mathrm{A}, \mathrm{B}, \mathrm{Ba}, \mathrm{D}$ and $\mathrm{E}$, are also phyletically closer than they are to $\mathrm{L} 2 k d t A$. The groEL sequence of $\mathrm{L} 2$ is phyletically almost as different from the serovar A groEL as it is from Chlamydia muridarum $\mathrm{MoPn}$ groEL. It would be inappropriate, therefore, to attempt to further separate the LGV biovar and the trachoma biovar using molecular criteria at the present time. The reference strain for the LGV biovar is L2/434/BU (ATCC VR 902B). The reference strain for the trachoma biovar is C/PK-2.

\section{Description of Chlamydia muridarum sp. nov., including hamster and mouse isolates previously belonging to Chlamydia trachomatis}

Chlamydia muridarum [mu.ri.da'rum. M.L. pl. gen. fem. n. muridarum of the Muridae (i.e. the mouse/ hamster family)].
Two strains of Chlamydia muridarum, MoPn and SFPD (Fox et al., 1993; Nigg, 1942; Stills et al., 1991), have been isolated from mice and hamsters. The recently reconstructed family Muridae includes both mice and hamsters (Alderton, 1996). The Chlamydia muridarum 16S rRNA genes that have been sequenced to date differ by $<0.13 \%$ (using updated SFPD sequence data), and their $16 \mathrm{~S}-23 \mathrm{~S}$ intergenic spacers and $23 \mathrm{~S}$ domain I segments are identical. Analyses of other gene sequences can also identify this species. Glycogen production by both strains has been demonstrated, although it is difficult to detect in MoPn (Moulder et al., 1984). MoPn has an extrachromosomal plasmid, pMoPn. Chlamydia muridarum MoPn binds mAbs recognizing Chlamydia trachomatis MOMP vs4 core epitope (T)LNPT(IA) (Peterson et al., 1991). DNA sequence analysis indicates that these mAbs should recognize SFPD and that Chlamydia trachomatis B-serogroup mAbs specific for the vs4 epitope IAGAG should recognize SFPD (Batteiger $e t$ al., 1996). MoPn was isolated in 1942 from the lungs of asymptomatic albino Swiss mice and was subsequently shown to be capable of producing disease in mice. SFPD was obtained from a hamster, concurrent with a causative agent of proliferative ileitis. MoPn has been shown to be sensitive to sulfadiazine. The type strain for Chlamydia muridarum is $\mathrm{MoPn}^{\mathrm{T}}(=\mathrm{ATCC} \mathrm{VR}$ $123^{\mathrm{T}}$ ).

\section{Description of Chlamydia suis sp. nov.}

Chlamydia suis (su'is. L. fem. n. sus pig; L. fem. gen. n. suis of the pig, because the only currently known natural host is Sus scrofa).

Chlamydia suis has recently been characterized and has only been isolated from swine. A high incidence of Chlamydia suis is being found in enteric porcine specimens, indicating that it may be endemic (Schiller et al., 1997; Szeredi et al., 1996; Zahn et al., 1995). The Chlamydia suis 16S rRNA genes that have been sequenced to date differ by $<1 \cdot 1 \%$. Glycogen has been detected in Chlamydia suis inclusions in infected swine tissues and in cell culture. Some strains have enhanced resistance to sulfadiazine and tetracycline (Andersen \& Rogers, 1998). Several strains of Chlamydia suis are known to have an extrachromosomal plasmid, pCS (Table 4). DNA sequence analysis of omp $A$ indicates that Chlamydia suis strains are somewhat more diverse than are other chlamydial species. The deduced $o m p A$ gene products of various Chlamydia suis strains contain vs4 epitopes TLNPTIAG(A/K/T)G(D/K/N/T), TWNPTIAGAGS or TLNPTISGKGQ. These epitopes are identical or nearly identical to the Chlamydia MOMP core epitopes NPTI, TLNPTI, LNPTIA or LNPTI, which are recognized by Chlamydia trachomatis vs4 mAbs; they are also identical or nearly identical to TIAGAGD and IAGAG epitopes, which are recognized by Chlamydia trachomatis B-serogroup mAbs (Batteiger et al., 1996). Chlamydia suis is associated with con- 
junctivitis, enteritis and pneumonia (Rogers \& Andersen, 1996; Rogers et al., 1996). The type strain for Chlamydia suis is S45 ${ }^{\mathrm{T}}\left(=\mathrm{ATCC}\right.$ VR $\left.1474^{\mathrm{T}}\right)$.

\section{Description of the genus Chlamydophila gen. nov.}

Chlamydophila (Chla.my.do'phil.a. Gr. fem. n. chlamys, chlamydis a cloak; L. fem. n. phila dear, beloved; M.L. fem. n. Chlamydophila dear to the cloak).

Chlamydophila is one of two genera in the Chlamydiaceae and is composed of the current species Chlamydia pecorum, Chlamydia pneumoniae and Chlamydia psittaci. These taxa, therefore, are renamed Chlamydophila pecorum, Chlamydophila pneumoniae and Chlamydophila psittaci. The complete 16S rRNA and 23S rRNA genes of Chlamydophila species are $\geqslant$ $95 \%$ identical. Chlamydophila species are readily identified and distinguished from other species by ribosomal signature sequences (Figs 3 and 4), or by inspection of the ribosomal intergenic spacer (Everett $\&$ Andersen, 1997). Any of several other genes may also be used to identify Chlamydophila species on the basis of DNA homology. The Chlamydophila genome is approximately $1.2 \mathrm{Mbp}$. Chlamydophila species do not produce detectable quantities of glycogen. The Chlamydophila genome is slightly larger than the Chlamydia genome and contains a single ribosomal operon (Fig. 5) (Fukushi \& Hirai, 1993; Scieux et al., 1992). Chlamydophila strains have varying morphology and varying resistance to sulfadiazine. Extrachromosomal plasmid is present in many Chlamydophila species (Table 4). The type species for the genus Chlamydophila is Chlamydophila psittaci.

\section{Emended description of Chlamydophila pecorum (Fukushi and Hirai 1992) comb. nov.}

The proposal to establish two genera in the family Chlamydiaceae necessitates transfer of the species Chlamydia pecorum, which has been described previously (Fukushi \& Hirai, 1992), to the species Chlamydophila pecorum comb. nov. The emended Chlamydophila pecorum strains have a high degree of ribosomal sequence conservation; Chlamydophila pecorum 16S rRNA genes that have been sequenced to date differ by $<0.6 \%$. Analyses of signature sequences (Figs 3 and 4) or of several other gene sequences can help identify this species. Two strains have been shown to have extrachromosomal plasmids (Table 4). Chlamydophila pecorum strains are generally noninvasive in a mouse model of virulence (Rodolakis et al., 1989; Rodolakis \& Souriau, 1992; A. Rodolakis, personal communication), but are serologically and pathogenically diverse. Chlamydophila pecorum strains characterized thus far have been limited to mammals, but not to a specific host family: Chlamydophila pecorum has been isolated from ruminants (cattle, sheep and goats) (Denamur et al., 1991; Fukushi \& Hirai, 1992), a marsupial (koala) (Girjes et al., 1993;
Glassick et al., 1996; M. Jackson et al., 1997) and swine (Anderson et al., 1996; Everett \& Andersen, 1997; Kaltenboeck \& Storz, 1992). In koalas, Chlamydophila pecorum causes reproductive disease, infertility and urinary tract disease. In other animals, Chlamydophila pecorum has been associated with abortion, conjunctivitis, encephalomyelitis, enteritis, pneumonia and polyarthritis (Anderson et al., 1996; Kaltenboeck et al., 1993). The type strain for Chlamydophila pecorum is E58 ${ }^{\mathrm{T}}$ (= ATCC VR $628^{\mathrm{T}}$ ).

\section{Description of Chlamydophila pneumoniae (Grayston, Kuo, Campbell and Wang 1989) comb. nov.}

The proposal to establish two genera in the family Chlamydiaceae necessitates transfer of the species Chlamydia pneumoniae (Grayston et al., 1989) to the species Chlamydophila pneumoniae comb. nov. Chlamydophila pneumoniae is considered to be primarily a respiratory pathogen. The emended species, Chlamydophila pneumoniae, has been isolated from humans worldwide (Kuo et al., 1995). In addition, a number of isolates obtained from koalas and a horse have genetic and antigenic characteristics very similar to the human isolates, which warrants including all of these in Chlamydophila pneumoniae (Glassick et al., 1996; Storey et al., 1993). DNA sequence analyses of omp $A$ indicate that the amino acid sequence of MOMP in all Chlamydophila pneumoniae strains varies $<6 \%$, while other species are $>30 \%$ different from Chlamydophila pneumoniae. The coherence of the Chlamydophila pneumoniae taxon has also been demonstrated by DNA sequence analysis of rRNA, $k d t A$ (KDO-transferase), and the $60 \mathrm{kDa}$ cysteine-rich gene. Partial analysis of any of these genes or analysis of signature sequences (Figs 3 and 4 ) can be used to identify this species. Only the equine strain, N16, has an extrachromosomal plasmid (pCpnE1). Three biovars, TWAR, Koala and Equine, are proposed within Chlamydophila pneumoniae, based on genetic and biological differences. The type strain for Chlamydophila pneumoniae is TW $-183^{\mathrm{T}}(=\mathrm{ATCC}$ VR $2282^{\mathrm{T}}$ ).

Chlamydophila pneumoniae, biovar TWAR. Previously, strain TWAR was synonymous with the designation of Chlamydia pneumoniae (Kuo et al., 1995). The description of biovar TWAR is identical to the description of the prototypical TWAR serovar (Grayston et al., 1989), except that biovar TWAR EBs may have either of two distinct ultrastructural morphologies: the prototypical pear-shaped EB (Grayston et al., 1989) or the classic coccoid morphology of the Chlamydiaceae spp. (Carter et al., 1991; Miyashita et al., 1993; Popov et al., 1991). The name TWAR was formed by merging the first two letters of isolates TW-183 and AR-39 (Grayston et al., 1989). TWAR strains have been obtained only from humans, form a distinct serovar, and are genetically almost indistinguishable (Kuo et al., 1995; Pettersson et al., 
1997). TWAR is primarily a pathogen of the respiratory tract, predominantly causing acute or chronic bronchitis and pneumonia. TWAR has also been associated with acute and chronic respiratory diseases such as otitis media, obstructive pulmonary disease and pulmonary exacerbation of cystic fibrosis. It has also been associated with Alzheimer's, atherosclerosis, asthma, erythema nodosum, reactive airway disease, Reiter's syndrome and sarcoidosis (Balin et al., 1998; Braun et al., 1997; Ellis, 1997; L. A. Jackson et al., 1997; Kuo et al., 1995). The reference strain for the TWAR biovar is TW-183 .

Chlamydophila pneumoniae, biovar Koala. Chlamydophila pneumoniae isolates obtained from the marsupial Phascolarctos cinereus have distinctive features that merit separation of the Koala biovar from the TWAR biovar. All isolates to date have only been obtained from Phascolarctos cinereus. The MOMP in the Koala biovar isolate designated 'Type I' is $2 \cdot 2 \%$ different from the protein homologue in TWAR, $5 \cdot 5 \%$ different from Equine MOMP, and $>30 \%$ different from MOMP in other chlamydial species. The KDOtransferase of Koala biovar Type I and TWAR differ by $<8 \%$ (Girjes et al., 1997), but are $>40 \%$ different from the $k d t A$ product in other chlamydial species. The TWAR mAb, CeLLabs-28E, does not recognize the Type I isolate (Girjes et al., 1994). Ultrastructural analyses of Type I EBs show the classic coccoid morphology of the Chlamydiaceae spp. (Girjes et al., 1993). The Koala biovar of Chlamydophila pneumoniae is further differentiated from other biovars of Chlamydophila pneumoniae by the sequence of variable segment 4 of ompA (Wardrop et al., 1999; eight isolates), the partial $60 \mathrm{kDa}$ cysteine-rich gene (Glassick et al., 1996; two isolates), and the groESL intergenic region (Wardrop et al., 1999). Chlamydiae belonging to the Koala biovar of Chlamydophila pneumoniae have been identified in all five Australian free-ranging koala populations that have been tested, including a colony that was suffering from respiratory disease. Isolates are commonly obtained from ocular and urogenital sites, where they do not appear to be highly pathogenic. The reference strain for the Koala biovar is LPCon.

Chlamydophila pneumoniae, biovar Equine. The Equine biovar of Chlamydophila pneumoniae currently includes only strain N16, which was isolated from the respiratory tract of a horse (Wills et al., 1990). The MOMP of N16 is $5.5 \%$ different from that in other Chlamydophila pneumoniae isolates (Storey et al., 1993) and $>30 \%$ different from other chlamydial species. The 16S rRNA of Chlamydophila pneumoniae strain N16 differs $1.1 \%$ from TWAR 16 S rRNA and $>4 \%$ from the 16S rRNA of other chlamydial species. N16 and TWAR $16 \mathrm{~S}-23 \mathrm{~S}$ intergenic spacer differ by $0.9 \%$, and they are $>11.3 \%$ different from other chlamydial species. The 23S rRNA Domain I of N16 and TWAR differ by $1.3 \%$, and are $>5.6 \%$ different from other chlamydial species. Two mAbs have been identified that are specific for the TWAR biovar, but that do not recognize N16 (Storey et al., 1993). Ultrastructural analyses of N16 EBs show the classic coccoid morphology of the Chlamydiaceae spp. (Wills et al., 1990). Inoculation of horses with N16 leads to asymptomatic infections (Mair \& Wills, 1992). The reference strain for the Equine biovar is N16.

\section{Description of Chlamydophila psittaci (Page 1968) comb. nov.}

Chlamydia psittaci, as previously described (Moulder et al., 1984), has been a taxon with considerable heterogeneity, having four groups that are phenotypically, pathogenically and genetically distinct. Only avian-like strains are being retained in Chlamydophila psittaci, with specific former Chlamydia psittaci abortion, feline and guinea pig strains being transferred into three new species. According to Rule $40 \mathrm{~b}$ of the International Code of Nomenclature of Bacteria, the original epithet for Chlamydia psittaci is retained by Chlamydophila psittaci because it contains avian strain $6 \mathrm{BC}^{\mathrm{T}}$, the original type strain (Lapage et al., 1992). As emended, Chlamydophila psittaci 16S rRNA genes differ by $<0.8 \%$. Analyses of other gene sequences can also help identify this species. Isolates are similar in virulence and grow readily in cell culture. All should be considered to be readily transmissible to humans. Several Chlamydophila psittaci strains have an extrachromosomal plasmid (Table 4). Many Chlamydophila psittaci strains are susceptible to bacteriophage Chpl (Storey et al., 1992). The type strain for Chlamydophila psittaci is $6 \mathrm{BC}^{\mathrm{T}}(=\mathrm{ATCC}$ VR $125^{\mathrm{T}}$ ).

The emended species, Chlamydophila psittaci, has eight known serovars that are readily distinguished using serovar-specific mAbs (Andersen, 1991, 1997; Vanrompay et al., 1993). These specific serovars can also be identified by omp $A$ sequence differences. Some serovars have a capability for infecting more than one type of host (Andersen et al., 1997; Centers for Disease Control and Prevention, 1997; Francis \& Magill, 1938; Page, 1967; Spalatin et al., 1966; Vanrompay et al., 1994). Serovar A is endemic among psittacine birds and causes sporadic zoonotic disease in humans. Serovar A infection of birds is often systemic and can be inapparent, severe, acute or chronic with intermittent shedding. Serovar B is endemic among pigeons, has been isolated from turkeys, and has also been identified as the cause of abortion in a dairy herd. Serovar C isolates GD, CT1 and Par1 were obtained from duck, turkey and partridge, respectively, so a specific avian host family has not been identified. Serovar D strains have been isolated from turkeys, a seagull, a budgerigar and humans. Serovars C and D are occupational hazards for slaughterhouse workers and for people in contact with birds. Serovar E isolates, known as Cal-10, MP or MN (meningopneumonitis), were first isolated during an outbreak of pneumonitis in humans in the late 1920s and early 1930s. Subsequently, $\mathrm{MN}$ isolates have been obtained from a 
variety of avian hosts worldwide, including ducks, pigeons, ostriches and rheas (Andersen et al., 1998). These isolations often come from ill or dying birds, and a specific reservoir for serovar $\mathrm{E}$ has not been identified. A single serovar F isolate, VS225, was obtained from a parakeet. The M56 serovar was isolated during an outbreak in muskrats and hares. The WC serovar was isolated during an outbreak of enteritis in cattle. Other monoclonal serotyping systems have also been developed (Fukushi et al., 1987; Takahashi et al., 1988, 1997), but a comparative study of these methods has not been done.

\section{Description of Chlamydophila abortus sp. nov., including abortion isolates previously belonging to Chlamydia psittaci}

Chlamydophila abortus (a.bor'tus. L. masc. gen. $\mathrm{n}$. abortus of miscarriage, referring to the principal symptom of infection).

Chlamydophila abortus strains are endemic among ruminants and efficiently colonize the placenta (Rodolakis et al., 1989). They have a distinctive serotype and nearly $100 \%$ conservation of ribosomal and omp $A$ sequences. The Chlamydophila abortus $16 \mathrm{~S}$ rRNA genes that have been sequenced to date differ by $<0.07 \%$. Analyses of signature sequences (Figs 3 and 4) or other gene sequences readily identify this species. An extrachromosomal plasmid has not been identified in any strain of Chlamydophila abortus. Chlamydophila abortus has been primarily associated with cases of abortion and weak neonates. Typical isolates include strains B577, EBA, OSP, S26/3 and A22 and have been obtained from cases of abortion in sheep, cattle and goats worldwide (Andersen, 1991; Denamur et al., 1991; Storz et al., 1960). Chlamydophila abortus isolates have also been characterized by serology and sequence analysis from cases of abortion in a horse, a rabbit, guinea pigs and mice (J. Storz, K. D. E. Everett, A. A. Andersen, unpublished data) and by PCR from a pig (Kaltenböck et al., 1997). Sporadic zoonotic abortion due to Chlamydophila abortus has been confirmed by genetic analysis of isolates from women who work with sheep (Herring et al., 1987; Jorgensen, 1997). The type strain for Chlamydophila abortus is B577 ${ }^{\mathrm{T}}$ (= ATCC VR $\left.656^{\mathrm{T}}\right) . \mathrm{B} 577^{\mathrm{T}}$ has a slightly divergent rDNA sequence compared to other Chlamydophila abortus strains.

\section{Description of Chlamydophila felis sp. nov., including feline isolates previously belonging to Chlamydia psittaci}

Chlamydophila felis (fe'lis. L. gen. n. felis of the cat, because the domestic cat is the primary host of the strains identified to date).

Chlamydophila felis is endemic among house cats worldwide, primarily causing conjunctivitis and rhinitis (Gaillard et al., 1984; TerWee et al., 1998). Chlamydophila felis strains are characterized by a high degree of rRNA and ompA conservation and have a distinctive serotype (Andersen, 1991; Pudjiatmoko et al., 1997; Sayada et al., 1994). The Chlamydophila felis 16S rRNA genes that have been sequenced to date differ by $<0.6 \%$. Strains FP Pring and FP Cello have an extrachromosomal plasmid, while the FP Baker strain does not. FP Cello produces lethal disease in mice while the FP Baker does not (May et al., 1996). An attenuated FP Baker strain is used as a live vaccine for cats. Zoonotic infection of humans with Chlamydophila felis has been reported (Schachter et al., 1969). The type strain for Chlamydophila felis is FP Baker $^{\mathrm{T}}\left(=\right.$ ATCC VR $\left.120^{\mathrm{T}}\right)$.

\section{Description of Chlamydophila caviae sp. nov., including guinea pig inclusion conjunctivitis isolates previously belonging to Chlamydia psittaci}

Chlamydophila caviae [ca'vi.ae. L. gen. fem. n. caviae of the guinea pig (Cavia cobaya) because the type strain was isolated from Cavia cobaya].

Chlamydophila caviae was first recovered from the conjunctiva of guinea pigs and the description of this species is identical to that of the isolate GPIC (Gordon et al., 1966; Murray, 1964; Prain \& Pearce, 1989). There are five known Chlamydophila caviae isolates, and the omp $A$ (ompl) sequences of these isolates are identical (Zhao et al., 1993). Analyses of signature sequences (Figs 3 and 4) or other gene sequences, including 16S rRNA, can be used to distinguish this species. GPIC contains an extrachromosomal plasmid, pCpGP1 (Lusher et al., 1989). The natural site of Chlamydophila caviae infection is the conjunctiva, however, it is possible to infect the genital tract of guinea pigs with Chlamydophila caviae and elicit a disease that is very similar to human genital infection. Chlamydophila caviae is markedly specific for guinea pigs, as attempts to infect mice, hamsters, rabbits and gerbils have been unsuccessful, except for one experimentally infected gerbil. Chlamydophila caviae infects primarily the mucosal epithelium and is not invasive. The type strain for Chlamydophila caviae is $\operatorname{GPIC}^{\mathrm{T}}\left(=\right.$ ATCC VR $\left.813^{\mathrm{T}}\right)$.

\section{Description of Parachlamydiaceae fam. nov.}

Parachlamydiaceae (Par.a.chla.my.di.a'ce.ae. M.L. fem. n. Parachlamydia type genus of the family; -aceae ending to denote a family; M.L. fem. pl. n. Parachlamydiaceae the Parachlamydia family).

The Parachlamydiaceae naturally infect amoebae and can be grown in cultured Vero cells. The Parachlamydiaceae are not recognized by monoclonal antibodies specific for the antigenic LPS trisaccharide $\alpha \mathrm{Kdo}-(2 \rightarrow 8)-\alpha \mathrm{Kdo}-(2 \rightarrow 4)-\alpha \mathrm{Kdo}$ of the Chlamydiaceae. The description of this family derives from the description of 'Candidatus Parachlamydia acanthamoebae' strain $\mathrm{Bn}_{9}{ }^{\mathrm{T}}$, strain $\mathrm{Berg}_{17}$ and several unnamed isolates (Amann et al., 1997; Birtles et al., 1997; Michel et al., 1994). The Parachlamydiaceae 
comprise strains with rRNAs that are $>90 \%$ identical to the ribosomal genes of strain $\mathrm{Bn}_{9}{ }^{\mathrm{T}}$. The Parachlamydiaceae belong to the order Chlamydiales and form a sister taxon to the Chlamydiaceae because they have a chlamydia-like cycle of replication and their ribosomal genes are $80-90 \%$ identical to ribosomal genes in the Chlamydiaceae. Phylogenetic analysis of a 16S rRNA from the Parachlamydiaceae gene has been published previously (Amann et al., 1997; Pettersson et al., 1997). At present, this family comprises but a single genus, the type genus Parachlamydia.

\section{Description of Parachlamydia (Amann, Springer, Schönhuber, Ludwig, Schmid, Müller and Michel 1997) gen. nov. 'Candidatus Parachlamydia' Amann, Springer, Schönhuber, Ludwig, Schmid, Müller and Michel 1997}

Parachlamydia (Par.a.chla.my'di.a. Gr. prep. para alike, alongside of; M.L. fem. n. Chlamydia taxonomic name of a bacterial genus).

Currently the description of Parachlamydia corresponds to the description of the family Parachlamydiaceae. Parachlamydia have variable Gram staining characteristics and are mesophilic. The $16 \mathrm{~S}$ and/or 23S rRNA genes of known members of Parachlamydia are $>95 \%$ identical to those of the type species, Parachlamydia acanthamoebae. New members of this genus should have $>95 \%$ rRNA sequence identity with Parachlamydia acanthamoebae.

\section{Description of Parachlamydia acanthamoebae sp. nov. 'Candidatus Parachlamydia acanthamoebae' Amann, Springer, Schönhuber, Ludwig, Schmid, Müller and Michel 1997}

Parachlamydia acanthamoebae [acan.tha.moe'bae. M.L. gen. sing. n. of Acanthamoeba taxonomic name of a genus of Acanthamoebidae; of (living in) members of the genus Acanthamoeba].

Parachlamydia acanthamoebae sp. nov. currently includes the type strain $\mathrm{Bn}_{9}{ }^{\mathrm{T}}$ (= ATCC VR $1476^{\mathrm{T}}$ ), isolate $\mathrm{Berg}_{17}$ and several unnamed isolates (Amann et al., 1997; Birtles et al., 1997; Michel et al., 1994). The 16S rRNA and rDNA of Parachlamydia acanthamoebae can be specifically detected with oligonucleotide probe $\mathrm{Bn}_{9} 658$ : 5' TCCGTTTTCTCCGCCTAC 3'. Trophozoites of Acanthamoeba hosting these strains were isolated from humans in an outbreak of humidifier fever in Vermont USA ('Hall's coccus') and also from asymptomatic women in Germany. In Nova Scotia, four patients whose sera recognized Hall's coccus did not show serological cross-reaction with antigens from the Chlamydiaceae (Birtles et al., 1997).

\section{Description of Simkaniaceae fam. nov.}

Simkaniaceae (Sim.ka.ni.a'ce.ae. M.L. fem. n. Simkania type genus of the family; -aceae ending to denote a family; M.L. fem. pl. n. Simkaniaceae the Simkania family).

The family Simkaniaceae currently comprises but a single genus, the type genus Simkania. The description of this family corresponds to that of the 'microorganism Z' (Kahane et al., 1993, 1995, 1999). The Simkaniaceae are not recognized by $\mathrm{mAbs}$ specific for the antigenic LPS trisaccharide $\alpha \mathrm{Kdo}-(2 \rightarrow 8)-\alpha \mathrm{Kdo}-$ $(2 \rightarrow 4)-\alpha \mathrm{Kdo}$ of the Chlamydiaceae. Simkaniaceae belongs to the order Chlamydiales and is a sister taxon of the Chlamydiaceae because it has a chlamydia-like cycle of replication and the ribosomal genes are $80-90 \%$ identical to ribosomal genes in the Chlamydiaceae. Phylogenetic analyses of the Simkaniaceae 16S rRNA gene have been published previously (Amann et al., 1997; Kahane et al., 1995; Pettersson et al., 1997). New strains belonging to the Simkaniaceae should have ribosomal genes that are $>90 \%$ identical to the ribosomal genes of strain $\mathrm{Z}^{\mathrm{T}}$. The type genus for Simkaniaceae is Simkania.

\section{Description of Simkania gen. nov.}

Simkania (Sim.ka'ni.a. M.L. fem. n. Simkania arbitrary name formed from the personal name Simona Kahane).

Currently the description of Simkania corresponds to the description of the family Simkaniaceae and includes a single isolate, strain $Z^{\mathrm{T}}$. The natural host of Simkania is not known, but serological evidence and PCR indicate that it is widespread among humans. New members of the genus Simkania should have 16S or $23 \mathrm{~S}$ rRNA genes that are $>95 \%$ identical to those of Simkania negevensis, the type species.

\section{Description of Simkania negevensis sp. nov.}

Simkania negevensis (ne.ge.ven'sis. M.L. adj. negevensis of or pertaining to the Negev, a desert in southern Israel).

The species Simkania negevensis currently includes only the type strain, Simkania negevensis strain $Z^{\mathrm{T}}$ (= ATCC VR $1471^{\mathrm{T}}$ ). Simkania negevensis was discovered as a bacterial contaminant in cell cultures. The description of this species is derived from that of the 'micro-organism Z' (Kahane et al., 1993, 1995, 1999). Strain $Z^{\mathrm{T}}$ does not contain an extrachromosomal plasmid and has an unusually slow developmental cycle in cultured Vero cells (up to $14 \mathrm{~d}$ ), compared to other chlamydiae. Unlike other chlamydial rRNA genes that have been characterized, Simkania negevensis has a group I intron in 23S rRNA position 1931 (E. coli numbering) and this intron is not spliced out of the rRNA. The intron is closely related to group I introns in the 23S rRNA of chloroplasts and mitochondria in algae and amoebae. 


\section{Rapid identification and classification of new chlamydial strains}

Identification of strains can be readily and accurately performed to determine whether a specimen belongs to one of the nine groups in the Chlamydiaceae, to Simkaniaceae, to Parachlamydiaceae, or is similar to strain WSU 86-1044. Three simple PCR methods have been described (Everett et al., 1999). Another simple method is to PCR-amplify and directly sequence the $16 \mathrm{~S}$ and/or 23S signature sequences from chromosomal template and to compare these data with Figs 3 or 4. When GenBank entries have been updated to reflect the new groups, identification of signature sequences will also be possible by using a BLAST search of that database. Because it is essential to have good sequence data to make these determinations, template preparations for PCR may need to be free of contamination with other bacterial templates or, alternatively, sequence data can be obtained from cloned gene segments. If other bacteria are present in the chlamydial isolate, hot-start PCR methods may partially alleviate the frequency of mismatch amplification of contaminating template. If cloning is necessary, a conserved $\mathrm{PbrPl}$ restriction site has been identified in the $23 \mathrm{~S}$ sequence to facilitate the selection of $23 \mathrm{~S}$ signature sequence clones (Fig. 4b). Sequence data not matching a species in Fig. 3 or 4 will represent either a novel isolate or a non-chlamydial organism. Novel isolates require more extensive phenotypic characterization and/or sequence analysis before they can be validly identified.

DNA sequence analysis of the ribosomal intergenic spacer or of non-ribosomal genes can be used to corroborate signature sequence identification of the Chlamydiaceae. Members of strains belonging to the family Chlamydiaceae are also identified using mAbs that recognize the trisaccharide antigen $\alpha \mathrm{Kdo}-(2 \rightarrow 8)$ $\alpha \mathrm{Kdo}-(2 \rightarrow 4)-\alpha \mathrm{Kdo}$, a unique component of the LPS and previously referred to as a genus-specific marker (Löbau et al., 1995).

\section{ACKNOWLEDGEMENTS}

The authors wish to thank Linda Hornung for the isolation of swine strains and for the propagation of other strains used in this work. We thank Wendy Hambly for technical assistance with ompA analysis. We thank Gary Polking, Harold 'Hal' Hills and Tim Ingram for providing outstanding data acquisition facilities. We thank Shirley M. Halling for making available sequence analysis software, computer time and radiolabelling facilities, and Richard L. Zuerner for providing PFGE equipment and assistance. We thank Pam Dilbeck and Fred Rurangirwa for making prepublication data available. We are gratefully indebted to Byron Batteiger, Bernhard Kaltenboeck, James W. Moulder, Roger G. Rank, Thaddeus Stanton, Johannes Storz, Peter Timms and Michael E. Ward for providing information and for their critical reviews of the preliminary drafts of this report. We also thank others who have contributed information in the compilation and review of these data and Karl Dyszynski for assistance in preparation of the manuscript. We thank Hans G. Trüper and Johannes
Storz for assisting with the naming of new taxa. We are honoured to comply with the requests of Rudolf Amann, Simona Kahane and Maureen G. Friedman that we formally classify their isolates in this proposal.

\section{REFERENCES}

Alderton, D. (1996). Rodents of the World. New York City: Facts On File.

Amann, R. I., Ludwig, W. \& Schleifer, K.-H. (1995). Phylogenetic identification and in situ detection of individual microbial cells without cultivation. Microbiol Rev 59, 143-169.

Amann, R., Springer, N., Schönhuber, W., Ludwig, W., Schmid, E. N., Müller, K. D. \& Michel, R. (1997). Obligate intracellular bacterial parasites of acanthamoebae related to Chlamydia spp. Appl Environ Microbiol 63, 115-121.

An, Q. \& Olive, D. M. (1994). Molecular cloning and nucleic acid squencing of Chlamydia trachomatis 16S rRNA genes from patient samples lacking the cryptic plasmid. Mol Cell Probes $\mathbf{8}$, 429-435.

An, Q., Radcliffe, G., Vassallo, R., Buxton, D., O'Brien, W. J., Pelletier, D. A., Weisburg, W. G., Klinger, J. D. \& Olive, D. M. (1992). Infection with a plasmid-free variant chlamydia related to Chlamydia trachomatis identified by using multiple assays for nucleic acid detection. $J$ Clin Microbiol 30, 2814-2821.

Andersen, A. A. (1991). Serotyping of Chlamydia psittaci isolates using serovar-specific monoclonal antibodies with the microimmunofluorescence test. J Clin Microbiol 29, 707-711.

Andersen, A. A. (1997). Two new serovars of Chlamydia psittaci from North American birds. J Vet Diagn Invest 9, 159-164.

Andersen, A. A. \& Rogers, D. G. (1998). Resistance to tetracycline and sulfadiazine in swine C. trachomatis isolates. In Proceedings of the Ninth International Symposium on Human Chlamydial Infections, pp. 313-316. Edited by R. S. Stephens, G. I. Byrne, G. Christiansen, I. N. Clarke, J. T. Grayston, R. G. Rank, G. L. Ridgway, P. Saikku, J. Schachter and W. E. Stamm. San Francisco, CA: International Chlamydia Symposium.

Anderson, I. E., Baxter, S. I. F., Dunbar, S., Rae, A. G., Philips, H. L., Clarkson, M. J. \& Herring, A. J. (1996). Analyses of the genomes of chlamydial isolates from ruminants and pigs support the adoption of the new species Chlamydia pecorum. Int $J$ Syst Bacteriol 46, 245-251.

Andersen, A. A., Grimes, J. E. \& Shivaprasad, H. L. (1998). Serotyping of $C$. psittaci isolates from ratites. Chlamydia psittaci. J Vet Diagn Invest 10, 186-188.

Balin, B. J., Gerard, H. C., Arking, E. J., Appelt, D. M., Branigan, P. J., Abrams, J. T., Whittum-Hudson, J. A. \& Hudson, A. P. (1998). Identification and localization of Chlamydiae pneumoniae in the Alzheimer's brain. Med Microbiol Immunol 187, 23-42.

Batteiger, B. E. (1996). The major outer membrane protein of a single Chlamydia trachomatis serovar can possess more than one serovar-specific epitope. Infect Immun 64, 542-547.

Batteiger, B. E., Lin, P. M., Jones, R. B. \& Van Der Pol, B. J. (1996). Species-, serogroup-, and serovar-specific epitopes are juxtaposed in variable sequence region 4 of the major outer membrane proteins of some Chlamydia trachomatis serovars. Infect Immun 64, 2839-2841.

Bergthorsson, U. \& Ochman, H. (1995). Heterogeneity of genome sizes among natural isolates of Escherichia coli. J Bacteriol 177 , 5784-5789.

Birkelund, S. \& Stephens, R. S. (1992). Construction of physical and genetic maps of Chlamydia trachomatis serovar L2 by pulsed-field gel electrophoresis. J Bacteriol 174, 2742-2747. 
Birtles, R. J., Rowbotham, T. J., Storey, C., Marrie, T. J. \& Raoult, D. (1997). Chlamydia-like obligate parasite of free-living amoebae. Lancet 349, 925-926.

Braun, J., Tuszewski, M., Eggens, U. \& 7 other authors (1997). Nested polymerase chain reaction strategy simultaneously targeting DNA sequences of multiple bacterial species in inflammatory joint diseases. I. Screening of synovial fluid samples of patients with spondyloarthropathies and other arthritides. $J$ Rheumatol 24, 1092-1100.

Brenner, D. J. and Falkow, S. (1971). Genetics of the Enterobacteriaceae. Molecular relationships among members of the Enterobacteriaceae. Adv Genet 16, 81-118.

Carter, M. W., al-Mahdawi, S. A. H., Giles, I. G., Treharne, J. D., Ward, M. E. \& Clarke, I. N. (1991). Nucleotide sequence and taxonomic value of the major outer membrane protein gene of Chlamydia pneumoniae IOL-207. J Gen Microbiol 137, 465-475.

Centers for Disease Control and Prevention (1997). Compendium of psittacosis (chlamydiosis) control. Morb Mortal Wkly Rep 46(RR-13), 1-13.

Cox, R. L., Kuo, C.-C., Grayston, J. T. \& Campbell, L. A. (1988). Deoxyribonucleic acid relatedness of Chlamydia sp. strain TWAR to Chlamydia trachomatis and Chlamydia psittaci. Int $J$ Syst Bacteriol 38, 265-268.

Darougar, S., Forsey, T., Brewerton, D. A. \& Rogers, K. L. (1980). Prevalence of antichlamydial antibody in London blood donors. Br J Vener Dis 56, 404407.

Denamur, E., Sayada, C., Souriau, A., Orfila, J., Rodolakis, A. \& Elion, J. (1991). Restriction pattern of the major outer-membrane protein gene provides evidence for a homogeneous invasive group among ruminant isolates of Chlamydia psittaci. $J$ Gen Microbiol 137, 2525-2530.

Dilbeck, P. M., Evermann, J. F., Crawford, T. B. \& 7 other authors (1990). Isolation of a previously undescribed rickettsia from an aborted bovine fetus. J Clin Microbiol 28, 814-816.

Dwyer, R. St. C., Treharne, J. D., Jones, B. R. \& Herring, J. (1972). Chlamydial infection. Results of micro-immunofluorescence tests for the detection of type-specific antibody in certain chlamydial infections. Br J Vener Dis 48, 452-459.

Ellis, R. W. (1997). Infection and coronary heart disease. $J$ Med Microbiol 46, 535-539.

Engel, J. N. \& Ganem, D. (1987). Chlamydial rRNA operons: gene organization and identification of putative tandem promoters. $J$ Bacteriol 169, 5678-5685.

Everett, K. D. E. \& Andersen, A. A. (1997). The ribosomal intergenic spacer and domain I of the 23S rRNA gene are phylogenetic markers for Chlamydia spp. Int $J$ Syst Bacteriol 47, 461-473.

Everett, K. D. E., Hornung, L. J. \& Andersen, A. A. (1999). Rapid detection of the Chlamydiaceae and other families in the order Chlamydiales: three PCR tests. J Clin Microbiol 37, 575-580.

Fan, H., Brunham, R. C. \& McClarty, G. (1992). Acquisition and synthesis of folates by obligate intracellular bacteria of the genus Chlamydia. J Clin Invest 90, 1803-1811.

Farencena, A., Comanducci, M., Donati, M., Ratti, G. \& Cevenini, R. (1997). Characterization of a new isolate of Chlamydia trachomatis which lacks the common plasmid and has properties of biovar trachoma. Infect Immun 65, 2965-2969.

Felsenstein, J. (1985). Confidence limits on phylogenies: an approach using the bootstrap. Evolution 39, 783-791.

Felsenstein, J. (1993). PHYLIP (Phylogeny Inference Package) version 3.5c. Distributed by the author. Department of Genetics, University of Washington, Seattle, USA.
Fitch, W. M., Peterson, E. M. \& de la Maza, L. M. (1993). Phylogenetic analysis of the outer- membrane-protein genes of chlamydiae, and its implication for vaccine development. $\mathrm{Mol}$ Biol Evol 10, 892-913.

Forsey, T. \& Darougar, S. (1984). Acute conjunctivitis caused by an atypical chlamydial strain: Chlamydia IOL 207. $\mathrm{Br} J$ Ophthalmol 68, 409-411.

Fox, J. G., Stills, H. F., Paster, B. J., Dewhirst, F. E., Yan, L., Palley, L. \& Prostak, K. (1993). Antigenic specificity and morphologic characteristics of Chlamydia trachomatis, strain SFPD, isolated from hamsters with proliferative ileitis. Lab Anim Sci 43, 405-410.

Francis, T., Jr \& Magill, T.P. (1938). An unidentified virus producing acute meningitis and pneumonia in experimental animals. J Exp Med 68, 147-160.

Fukushi, H. \& Hirai, K. (1989). Genetic diversity of avian and mammalian Chlamydia psittaci strains and relation to host origin. J Bacteriol 171, 2850-2855.

Fukushi, H. \& Hirai, K. (1992). Proposal of Chlamydia pecorum sp. nov. for Chlamydia strains derived from ruminants. Int $J$ Syst Bacteriol 42, 306-308.

Fukushi, H. \& Hirai, K. (1993). Restriction fragment length polymorphisms of rRNA as genetic markers to differentiate Chlamydia spp. Int J Syst Bacteriol 43, 613-617.

Fukushi, H., Nojiri, K. \& Hirai, K. (1987). Monoclonal antibody typing of Chlamydia psittaci strains derived from avian and mammalian species. J Clin Microbiol 25, 1978-1981.

Gaillard, E. T., Hargis, A. M., Prieur, D. J., Evermann, J. F. \& Dhillon, A. S. (1984). Pathogenesis of feline gastric chlamydial infection. Am J Vet Res 45, 2314-2321.

Garrett, A. J. (1975). Some properties of the polysaccharide from cell cultures infected with TRIC agent (Chlamydia trachomatis). J Gen Microbiol 90, 133-139.

Gautom, R., Herwig, R. \& Fritsche, T. (1996). Molecular phylogeny of bacterial endosymbionts of Acanthamoeba spp. Abstr Gen Meet Am Soc Microbiol 96, 474.

Genetics Computer Group (1994). Program Manual for the Wisconsin Package, version 8. Genetics Computer Group, Madison, WI, USA.

GENSET (1997). GENSET sequences Chlamydia pneumoniae for cardiovascular research. GENSET Press Release. http://www.genxy.com/News/Releases/chlamydia.html/

Girjes, A. A., Hugall, A., Timms, P. \& Lavin, M. F. (1988). Two distinct forms of Chlamydia psittaci associated with disease and infertility in Phascolarctos cinereus (Koala). Infect Immun 56, 1897-1900.

Girjes, A. A., Hugall, A., Graham, D. M., McCaul, T. F. \& Lavin, M. F. (1993). Comparison of type I and type II Chlamydia psittaci strains infecting koalas (Phascolarctos cinereus). Vet Microbiol 37, 65-83.

Girjes, A. A., Carrick, F. N. \& Lavin, M. F. (1994). Remarkable sequence relatedness in the DNA encoding the major outer membrane protein of Chlamydia psittaci (koala type I) and Chlamydia pneumoniae. Gene 138, 139-142.

Girjes, A. A., Carrick, F. N. \& Lavin, M. F. (1997). Lipopolysaccharide biosynthesis genes in koala type I Chlamydia: cloning and characterization. Res Microbiol 148, 413-425.

Glassick, T., Giffard, P. \& Timms, P. (1996). Outer membrane protein 2 gene sequences indicate that Chlamydia pecorum and Chlamydia pneumoniae cause infections in koalas. Syst Appl Microbiol 19, 457-464. 
Gordon, F. B., Weiss, E., Quan, A. L. \& Dressler, H. R. (1966). Observations on guinea pig inclusion conjunctivitis agent. $J$ Infect Dis 116, 203-207.

Grayston, J. T., Kuo, C.-C., Campbell, L. A. \& Wang, S.-P. (1989). Chlamydia pneumoniae sp. nov. for Chlamydia sp. strain TWAR. Int J Syst Bacteriol 39, 88-90.

Hackstadt, T., Fischer, E. R., Scidmore, M. A., Rockey, D. D. \& Heinzen, R. A. (1997). Origins and functions of the chlamydial inclusion. Trends Microbiol 5, 288-293.

Herring, A. J. (1993). Typing Chlamydia psittaci-a review of methods and recent findings. Br Vet $J 149,455-475$.

Herring, A. J., Anderson, I. E., McClenaghan, M., Inglis, N. F., Williams, H., Matheson, B. A., West, C. P., Rodger, M. \& Brettle, R. P. (1987). Restriction endonuclease analysis of DNA from two isolates of Chlamydia psittaci obtained from human abortions. Brit Med J 295, 1239.

Jackson, L. A., Campbell, L. A., Kuo, C. C., Rodriguez, D. I., Lee, A. \& Grayston, J. T. (1997). Isolation of Chlamydia pneumoniae from a carotid endarterectomy specimen. J Infect Dis 176, $292-295$

Jackson, M., Giffard, P. \& Timms, P. (1997). Outer membrane protein A gene sequencing demonstrates the polyphyletic nature of koala Chlamydia pecorum isolates. Syst Appl Microbiol 20, $187-200$

Jorgensen, D. M. (1997). Gestational psittacosis in a Montana sheep rancher. Emerg Infect Dis 3, 191-194.

Joseph, T., Nano, F. E., Garon, C. F. \& Caldwell, H. D. (1986). Molecular characterization of Chlamydia trachomatis and Chlamydia psittaci plasmids. Infect Immun 51, 699-703

Jukes, T. H. \& Cantor, C. R. (1969). Evolution of protein molecules. In Mammalian Protein Metabolism, vol. III, pp. 21-132. Edited by H. N. Munro. New York: Academic Press.

Kahane, S., Gonen, R., Sayada, C., Elion, J. \& Friedman, M. G. (1993). Description and partial characterization of a new chlamydia-like microorganism. FEMS Microbiol Lett 109 , 329-334

Kahane, S., Metzer, E. \& Friedman, M. G. (1995). Evidence that the novel microorganism ' $Z$ ' may belong to a new genus in the family Chlamydiaceae. FEMS Microbiol Lett 126, 203-208.

Kahane, S., Everett, K. D. E., Kimmel, N. \& Friedman, M. G. (1999). Simkania negevensis strain $\mathrm{Z}^{\mathrm{T}}$ : growth, antigenic and genome characteristics. Int J Syst Bacteriol 49, 815-820.

Kaltenboeck, B. \& Storz, J. (1992). Biological properties and genetic analysis of the omp $A$ locus in chlamydiae isolated from swine. $J$ Vet Res 53, 1482-1487.

Kaltenboeck, B., Kousoulas, K. G. \& Storz, J. (1993). Structures of and allelic diversity and relationships among the major outer membrane protein (omp $A$ ) genes of the four chlamydial species. $J$ Bacteriol 175, 487-502

Kaltenböck, B., Schmeer, N. \& Schneider, R. (1997). Evidence for numerous ompl alleles of porcine Chlamydia trachomatis and novel chlamydial species obtained by PCR. J Clin Microbiol 35, 1835-1841.

Kingsbury, D. T. \& Weiss, E. (1968). Lack of deoxyribonucleic acid homology between species of the genus Chlamydia. $J$ Bacteriol 96, 1421-1423.

Kocan, K. M., Crawford, T. B., Dilbeck, P. M., Evermann, J. F. \& McGuire, T. C. (1990). Development of a rickettsia isolated from an aborted bovine fetus. J Bacteriol 172, 5949-5955.

Kuo, C.-C., Jackson, L. A., Campbell, L. A. \& Grayston, J. T. (1995).
Chlamydia pneumoniae (TWAR). Clin Microbiol Rev 8, 451-461.

Lapage, S. P., Sneath, P. H. A., Lessel, E. F., Skerman, V. B. D., Seeliger, H. P. R. \& Clark, W. A. (editors) (1992). International Code of Nomenclature of Bacteria (1990 Revision). Bacteriological Code. Washington, DC: American Society for Microbiology.

Levene, S. D. \& Zimm, B. H. (1987). Separations of open-circular DNA using pulsed-field electrophoresis. Proc Natl Acad Sci USA 84, 4054-4057.

Lin, H.-S. \& Moulder, J.W. (1966). Patterns of response to sulfadiazine, D-cycloserine and D-alanine in members of the psittacosis group. $J$ Infect Dis 116, 372-376.

Löbau, S., Mamat, U., Brabetz, W. \& Brade, H. (1995). Molecular cloning, sequence analysis, and functional characterization of the lipopolysaccharide biosynthetic gene $k d t A$ encoding 3deoxy-alpha-D-manno-octulosonic acid transferase of Chlamydia pneumoniae strain TW-183. Mol Microbiol 18, 391-399.

Lusher, M., Storey, C. C. \& Richmond, S. J. (1989). Plasmid diversity within the genus Chlamydia. J Gen Microbiol 135, $1145-1151$

Mair, T. S. \& Wills, J. M. (1992). Chlamydia psittaci infection in horses: results of a prevalence survey and experimental challenge. Vet Rec 130, 417-419.

May, S. W., Kelling, C. L., Sabara, M. \& Sandbulte, J. (1996). Virulence of feline Chlamydia psittaci in mice is not a function of the major outer membrane protein. Vet Microbiol 53, 355-368.

Michel, R., Hauröder-Philippczyk, B., Müller, K.-D. \& Weishaar, I. (1994). Acanthamoeba from human nasal mucosa infected with an obligate intracellular parasite. Eur J Protistol 30, 104-110.

Miyashita, N., Kanamoto, Y. \& Matsumoto, A. (1993). The morphology of Chlamydia pneumoniae. J Med Microbiol 38, 418-425.

Moulder, J. W. (1991). Interaction of chlamydiae and host cells in vitro. Microbiol Rev 55, 143-190.

Moulder, J. W., Hatch, T. P., Kuo, C.-C., Schachter, J. \& Storz, J. (1984). Genus Chlamydia. In Bergey's Manual of Systematic Bacteriology, vol. 1, pp. 729-739. Edited by N. R. Krieg. Baltimore: Williams \& Wilkins.

Murray, E. S. (1964). Guinea pig inclusion conjunctivitis virus. I. Isolation and identification as a member of the psittacosislymphogranuloma-trachoma group. J Infect Dis 114, 1-12.

Nigg, C. (1942). Unidentified virus which produces pneumonia and systemic infection in mice. Science 95, 49-50.

Nordström, K. (1990). Control of plasmid replication - how do DNA iterons set the replication frequency? Cell 63, 1121-1124.

van Ooij, C., Apodaca, G. \& Engel, J. (1997). Characterization of the Chlamydia trachomatis vacuole and its interaction with the host endocytic pathway in HeLa cells. Infect Immun 65, 758-766.

Page, L. A. (1966). Revision of the family Chlamydiaceae Rake (Rickettsiales): unification of the psittacosis-lymphogranuloma venereum-trachoma group of organisms in the genus Chlamydia, Jones, Rake and Stearns, 1945. Int J Syst Bacteriol 16, 223-252.

Page, L. A. (1967). Comparison of "pathotypes" among chlamydial (psittacosis) strains recovered from diseased birds and mammals. Bull Wildlife Dis Assoc 2, 166-175. 
Page, L. A. (1968). Proposal for the recognition of two species in the genus Chlamydia. Jones, Rake, and Stearns, 1945. Int J Sys Bacteriol 18, 51-66.

Palys, T., Nakamura, L. K. \& Cohan, F. M. (1997). Discovery and classification of ecological diversity in the bacterial world: the role of DNA sequence data. Int J Syst Bacteriol 47, 1145-1156.

Peterson, E. M., Markoff, B. A., Schachter, J. \& de la Maza, L. M. (1990). The $7 \cdot 5-\mathrm{kb}$ plasmid present in Chlamydia trachomatis is not essential for the growth of this microorganism. Plasmid 23, 144-148.

Peterson, E. M., Cheng, X., Markoff, B. A., Fielder, T. J. \& de la Maza, L. M. (1991). Functional and structural mapping of Chlamydia trachomatis species-specific major outer membrane protein epitopes by use of neutralizing monoclonal antibodies. Infect Immun 59, 4147-4153.

Pettersson, B., Andersson, A., Leitner, T., Olsvik, O., Uhlén, M., Storey, C. \& Black, C. M. (1997). Evolutionary relationships among members of the genus Chlamydia based on $16 \mathrm{~S}$ ribosomal DNA analysis. $J$ Bacteriol 179, 4195-4205.

Popov, V. L., Shatkin, A. A., Pankratova, V. N., Smirnova, N. S., von Bonsdorff, C.-H., Ekman, M.-R., Mörttinen, A. \& Saikku, P. (1991). Ultrastructure of Chlamydia pneumoniae in cell culture. FEMS Microbiol Lett 84, 129-145.

Prain, C. J. \& Pearce, J. H. (1989). Ultrastructural studies on the intracellular fate of Chlamydia psittaci (strain guinea pig inclusion conjunctivitis) and Chlamydia trachomatis (strain lymphogranuloma venereum 434): modulation of intracellular events and relationship with endocytic mechanism. $J$ Gen Microbiol 135, 2107-2123.

Pudjiatmoko, Fukushi, H., Ochiai, Y., Yamaguchi, T. \& Hirai, K. (1997). Phylogenetic analysis of the genus Chlamydia based on 16S rRNA gene sequences. Int J Syst Bacteriol 47, 425-431.

Rake, G. W. (1957). Family II. Chlamydiaceae Rake, Fam. Nov. In Bergey's Manual of Systematic Bacteriology, 7th edn, pp. 957-968. Edited by R. S. Breed, E. G. D. Murray \& N. R. Smith. Baltimore: Williams \& Wilkins.

Rodolakis, A. \& Souriau, A. (1992). Restriction endonuclease analysis of DNA from ruminant Chlamydia psittaci and its relation to mouse virulence. Vet Microbiol 31, 263-271.

Rodolakis, A., Bernard, F. \& Lantier, F. (1989). Mouse models for evaluation of virulence of Chlamydia psittaci isolated from ruminants. Res Vet Sci 46, 34-39.

Rogers, D. G. \& Andersen, A. A. (1996). Intestinal lesions caused by two swine chlamydial isolates in gnotobiotic pigs. $J$ Vet Diagn Invest 8, 433-440.

Rogers, D. G., Andersen, A. A., Hogg, A., Nielsen, D. L. \& Huebert, M. A. (1993). Conjunctivitis and keratoconjunctivitis associated with chlamydiae in swine. J Am Vet Med Assoc 203, 1321-1323.

Rogers, D. G., Andersen, A. A. \& Hunsaker, B. D. (1996). Lung and nasal lesions caused by a swine chlamydial isolate in gnotobiotic pigs. $J$ Vet Diagn Invest $\mathbf{8}, 45-55$.

Rurangirwa, F. R., Dilbeck, P. M., Crawford, T. B., McGuire, T. C. \& McElwain, T. F. (1999). Analysis of the 16S rRNA gene of micro-organism WSU 86-1044 from an aborted bovine foetus reveals that it is a member of the order Chlamydiales: proposal of Waddliaceae fam. nov., Waddlia chondrophila gen. nov., sp. nov. Int $J$ Syst Bacteriol 49, 577-581.

Sakamoto, T. \& Bryant, D. A. (1998). Growth at low temperature causes nitrogen limitation in the cyanobacterium Synechococcus sp. PCC 7002. Arch Microbiol 169, 10-19.
Sambrook, J., Fritsch, E. F. \& Maniatis, T. (1989). Molecular Cloning: a Laboratory Manual, 2nd edn. Cold Spring Harbor, NY: Cold Spring Harbor Laboratory.

Sayada, C., Andersen, A., Rodriguez, P., Eb, F., Milon, A., Elion, J. \& Denamur, E. (1994). Homogeneity of the major outer membrane protein gene of feline Chlamydia psittaci. Res Vet Sci 56, 116-118.

Schachter, J., Ostler, H. B. \& Meyer, K. F. (1969). Human infection with the agent of feline pneumonitis. Lancet 1, 1063-1065.

Schiller, I., Koesters, R., Weilenmann, R., Kaltenboeck, B. \& Pospischil, A. (1997). Polymerase chain reaction (PCR) detection of porcine Chlamydia trachomatis and ruminant Chlamydia psittaci serovar 1 DNA in formalin-fixed intestinal specimens from swine. J Vet Med Ser B 44, 185-191.

Schleifer, K. H. \& Stackebrandt, E. (1983). Molecular systematics of prokaryotes. Annu Rev Microbiol 37, 143-87.

Scieux, C., Grimont, F., Regnault, B. \& Grimont, P. A. D. (1992). DNA fingerprinting of Chlamydia trachomatis by use of ribosomal RNA, oligonucleotide and randomly cloned DNA probes. Res Microbiol 143, 755-765.

Skerman, V. B. D., McGowan, V. \& Sneath, P. H. A. (1980). Approved lists of bacterial names. Int J Syst Bacteriol 30, 225-420.

Spalatin, J., Fraser, C. E. O., Connell, R., Hanson, R. P. \& Berman, D. T. (1966). Agents of psittacosis-lymphogranuloma venereum group isolated from muskrats and snowshoe hares in Saskatchewan. Can J Comp Med Vet Sci 30, 260-264.

Stackebrandt, E., Rainey, F. A. \& Ward-Rainey, N. L. (1997). Proposal for a new hierarchic classification system, Actinobacteria classis nov. Int $J$ Syst Bacteriol 47, 479-491.

Stephens, R. S., Kalman, S., Lammel, C. \& 9 other authors (1998). Genome sequence of obligate intracellular pathogen of humans: Chlamydia trachomatis. Science 282, 754-759.

Stills, H. F., Jr, Fox, J. G., Paster, B. J. \& Dewhirst, F. E. (1991). A "new" Chlamydia sp. strain SFPD isolated from transmissible proliferative ileitis in hamsters. Microbiol Ecol Health Dis 4, S99.

Storey, C., Lusher, M. \& Richmond, S. J. (1992). Use of comparative MOMP gene sequence data for subdivision of Chlamydia psittaci species. In Proceedings of the European Society for Chlamydia Research, pp. 191. Edited by P.-A. Mårdh, M. LaPlaca \& M. Ward. Uppsala, Sweden: Uppsala University Centre for STD Research.

Storey, C., Lusher, M., Yates, P. \& Richmond, S. (1993). Evidence for Chlamydia pneumoniae of non-human origin. $J$ Gen Microbiol 139, 2621-2626.

Storz, J. \& Page, L. A. (1971). Taxonomy of the chlamydiae: reasons for classifying organisms of the genus Chamydia family Chlamydiaceae, in a separate order, Chlamydiales ord. nov. Int $J$ Syst Bacteriol 21, 332-334.

Storz, J., McKercher, D. G., Howarth, J. A. \& Straub, O. C. (1960). The isolation of a viral agent from epizootic bovine abortion. $J$ Am Vet Med Assoc 137, 509-514.

Swofford, D. L. (1993). PAUP: phylogenetic analysis using parsimony. Version 3.1. Computer program distributed by the Illinois Natural History Survey, Champaign, IL, USA.

Szeredi, L., Schiller, I., Sydler, T., Guscetti, F., Heinen, E., Corboz, L., Eggenberger, E., Jones, G. E. \& Pospischil, A. (1996). Intestinal Chlamydia in finishing pigs. Vet Pathol 33, 369-374.

Takahashi, T., Takashima, I. \& Hashimoto, N. (1988). Immunotyping of Chlamydia psittaci by indirect immunofluorescence 
antibody test with monoclonal antibodies. Microbiol Immunol 32, 251-263.

Takahashi, T., Masuda, M., Tsuruno, T., Mori, Y., Takashima, I., Hiramune, T. \& Kikuchi, N. (1997). Phylogenetic analyses of Chlamydia psittaci from birds based on 16S rDNA gene sequence. J Clin Microbiol 35, 2908-2914.

Taraska, T., Ward, D. M., Ajioka, R. S., Wyrick, P. B., DavisKaplan, S. R., Davis, C. H. \& Kaplan, J. (1996). The late chlamydial inclusion membrane is not derived from the endocytic pathway and is relatively deficient in host proteins. Infect Immun 64, 3713-3727.

TerWee, J., Sabara, M., Kokjohn, K., Sandbulte, J., Frenchick, P. \& Dreier, K. J. (1998). Characterization of the systemic disease and ocular signs induced by experimental infection with Chlamydia psittaci in cats. Vet Microbiol 59, 259-281.

Thomas, N. S., Lusher, M., Storey, C. C. \& Clarke, I. N. (1997). Plasmid diversity in Chlamydia. Microbiology 143, 1847-1854.

Thompson, J. D., Higgins, D. G. \& Gibson, T. J. (1994). CLUSTAL $\mathrm{W}$ : improving the sensitivity of progressive multiple sequence alignment through sequence weighting, position-specific gap penalties and weight matrix choice. Nucleic Acids Res 22, 4673-4680.

Timms, P., Eaves, F. W., Girjes, A. A. \& Lavin, M. F. (1988). Comparison of Chlamydia psittaci isolates by restriction endonuclease and DNA probe analysis. Infect Immun 56, 287-290.

Van de Peer, Y., Neefs, J.-M., De Rijk, P., De Vos, P. \& De Wachter, R. (1994). About the order of divergence of the major bacterial taxa during evolution. Syst Appl Microbiol 17, 32-38.

Vanrompay, D., Andersen, A. A., Ducatelle, R. \& Haesebrouck, F. (1993). Serotyping of European isolates of Chlamydia psittaci from poultry and other birds. J Clin Microbiol 31, 134-137.

Vanrompay, D., De Meurichy, W., Ducatelle, R. \& Haesebrouck, F. (1994). Pneumonia in Moorish tortoises (Testudo graeca) associated with avian serovar A Chlamydia psittaci. Vet Rec 135, 284-285.

Vuillaumier, S., Kaltenboeck, B., Lecointre, G., Lehn, P. \&
Denamur, E. (1997). Phylogenetic analysis of cystic fibrosis transmembrane conductance regulator gene in mammalian species argues for the development of a rabbit model for cystic fibrosis. Mol Biol Evol 14, 372-380.

Walker, E. M., Arnett, J. K., Heath, J. D. \& Norris, S. J. (1991). Treponema pallidum subsp. pallidum has a single, circular chromosome with a size of approximately 900 kilobase pairs. Infect Immun 59, 2476-2479.

Wardrop, S., Fowler, A., O'Callaghan, P., Giffard, P. \& Timms, P. (1999) Characterisation of the koala biovar of Chlamydia pneumoniae at four gene loci. Syst Appl Microbiol (in press).

Wayne, L. G., Brenner, D. J., Colwell, R. R. \& 9 other authors (1987). International Committee on Systematic Bacteriology. Report of the ad hoc committee on reconciliation of approaches to bacterial systematics. Int J Syst Bacteriol 37, 463-464.

Weisburg, W. G., Hatch, T. P. \& Woese, C. R. (1986). Eubacterial origin of chlamydiae. $J$ Bacteriol 167, 570-574.

Weiss, E., Schramek, S., Wilson, N. N. \& Newman, L. W. (1970), Deoxyribonucleic acid heterogeneity between human and murine strains of Chlamydia trachomatis. Infect Immun 2, 24-28.

Wills, J. M., Watson, G., Lusher, M., Mair, T. S., Wood, D. \& Richmond, S. J. (1990). Characterisation of Chlamydia psittaci isolated from a horse. Vet Microbiol 24, 11-19.

Zahn, I., Szeredi, L., Schiller, I. \& 7 other authors (1995). Immunohistochemical determination of Chlamydia psittaci) pecorum and C. trachomatis in the piglet gut. J Vet Med Ser B 42, 266-276.

Zhang, Y.-X., Fox, J. G., Ho, Y., Zhang, L., Stills, H. F., Jr \& Smith, T. F. (1993). Comparison of the major outer-membrane protein (MOMP) gene of mouse pneumonitis (MoPn) and hamster SFPD strains of Chlamydia trachomatis with other Chlamydia strains. Mol Biol Evol 10, 1327-1342.

Zhao, Q., Schachter, J. \& Stephens, R. S. (1993). Lack of allelic polymorphism for the major outer membrane protein gene of the agent of guinea pig inclusion conjunctivitis (Chlamydia psittaci). Infect Immun 61, 3078-3080. 